NBER WORKING PAPER SERIES

\title{
THE ASSIGNMENT OF WORKERS TO JOBS IN AN ECONOMY WITH COORDINATION FRICTIONS
}

\author{
Robert Shimer \\ Working Paper 8501 \\ http://www.nber.org/papers/w8501 \\ NATIONAL BUREAU OF ECONOMIC RESEARCH \\ 1050 Massachusetts Avenue \\ Cambridge, MA 02138 \\ October 2001
}

I am grateful to Jaap Abbring, Daron Acemoglu, James Heckman, Ian King, Shouyong Shi, and Chris Sims for useful discussions. I have also benefited from comments by many seminar participants at the NBER Summer Institute 2001, the Minnesota Workshop in Macro Theory, and Princeton. I thank the University of Chicago for its hospitality in April and May 2001 while I wrote the first draft of this paper, the National Science Foundation for financial support, and Sebastian Ludmer for excellent research assistance. The views expressed herein are those of the author and not necessarily those of the National Bureau of Economic Research.

(C) 2001 by Robert Shimer. All rights reserved. Short sections of text, not to exceed two paragraphs, may be quoted without explicit permission provided that full credit, including (C) notice, is given to the source. 
The Assignment of Workers to Jobs In an Economy with Coordination Frictions

Robert Shimer

NBER Working Paper No. 8501

October 2001

JEL No. E24, J64, J41, J21

\begin{abstract}
$\underline{\text { ABSTRACT }}$
This paper studies the assignment of heterogeneous workers to heterogeneous jobs in the presence of coordination frictions. Firms offer human-capital-contingent wages, workers observe these and apply for a job. In a symmetric equilibrium, identical workers use identical mixed strategies in deciding where to apply, and the randomness introduced by mixed strategies generates equilibrium unemployment and vacancies. The equilibrium can be interpreted as the competitive equilibrium of a closely related model, ensuring constrained efficiency. The model generates a rich interaction between the heterogeneous workers and firms. Firms attract applications from multiple types of workers, and earn higher profits when they hire a more productive worker. Identical workers apply for jobs with different productivity and get higher wages when they land a more productive job. Despite this mismatch, I show that in some special cases, the model generates assortative matching, with a positive correlation between matched workers' and firms' productivity.
\end{abstract}

\author{
Robert Shimer \\ Department of Economics \\ Princeton University \\ Princeton, NJ 08544 \\ and NBER \\ shimer@princeton.edu
}




\section{Introduction}

How does the labor market assign workers to jobs? Koopmans and Beckmann (1957) and Shapley and Shubik (1972) first explored this question, proving that the core allocation of an assignment game is equivalent to an appropriately defined competitive equilibrium. ${ }^{1}$ This model yields a number of very powerful predictions. Identical workers should earn the same wage, even if they take different types of jobs. Identical firms should earn the same profits, even if they hire different types of workers. If workers' and firms' characteristics are complements in production, a more productive worker should always have a better job than a less productive one (Becker 1973). Unemployment and vacant jobs cannot coexist. If there is unemployment, only the least productive workers will be unemployed, while if there are vacancies, only the least productive firms will fail to hire a worker.

These predictions are inconsistent with existing empirical evidence. For example, consider a panel data regression of wages on an individual fixed effect, any time varying worker characteristics, and on some measure of the quality of the worker's job. The individual fixed effect should soak up any observable or unobservable time-invariant individual characteristics, and so the textbook assignment model predicts that the quality of the worker's job should not affect her wage. On the contrary, the data indicates that workers in better quality jobs consistently earn higher wages (Krueger and Summers 1988, Gibbons and Katz 1992, Abowd, Kramarz, and Margolis 1999). Similarly, firms' profits appear to depend on the quality of their employees. The other stark predictions fail as well. Although on average more productive workers have better jobs than less productive ones, that is not true on a case-by-case basis. Unemployment and vacancies coexist, high productivity workers are sometimes unemployed, and high productivity jobs sometimes go unfilled.

This paper asks how large a departure one requires from the textbook assignment model in order to explain these facts. The short answer is 'not much'. I consider an economy consisting of a continuum of risk-neutral workers, each characterized by one of $N$ different human capital levels, and a continuum of risk-neutral firms with heterogeneous levels of physical capital described by an arbitrary distribution. Each firm has a single vacancy to fill, and towards that end, firms simultaneously commit to wages that they will pay a worker as a function of her human capital. Workers observe all the wage offers and each simultaneously applies for one job. Firms that receive at least one application select one

\footnotetext{
${ }^{1}$ Sattinger (1993) and Roth and Sotomayor (1990) provide comprehensive reviews of the literature on matching with transferable and non-transferable utility, respectively.
} 
worker, pay her the promised wage, and produce. Workers whose application is rejected are unemployed and do not get paid, while jobs that fail to hire a worker remain vacant and do not produce.

The core allocation is one equilibrium of this model. All firms offer workers the competitive wage, and workers apply for different jobs, with the same assignment as in the core. While it is consistent with the rules of the game, this equilibrium relies very heavily on everybody knowing exactly what everyone else is doing. In particular, two workers with the same human capital must know which of them is supposed to apply for which job. To capture the notion that this level of coordination may be infeasible in a large economy, I introduce a symmetry restriction on strategies: in equilibrium, identical workers must use identical application strategies. If workers used pure strategies, a positive mass of workers would apply for each of $N$ different jobs, while every other job would go unfilled. This cannot be an equilibrium, and so instead workers use mixed strategies in deciding where to apply for a job. Workers' independent mixing implies that some jobs attract more than one applicant while other identical jobs attract none, generating equilibrium unemployment and vacancies.

Montgomery (1991), Peters (1991), and Burdett, Shi, and Wright (2001) have explored a similar environment, although all of these papers assume workers are homogeneous, thus precluding a study of the assignment issues that are central to this paper. I extend those earlier works to an environment with heterogeneous workers and jobs and an arbitrary production function. Section 4 focuses on how a single firm sets its wage schedule, taking as given the actions of the other firms and the response of workers to changes in its wage schedule. I show that the firm's expected revenue is a concave function of the expected number of applications it receives from each type of worker, while its cost is linear in these variables. This insight yields a useful alternative representation of the firm's problem. The firm effectively chooses the expected number of each type of applicant in order to maximize its expected profits, setting the expected marginal product of an application equal to the marginal cost. Using the solution to this alternative problem, I then back out the firm's underlying wage schedule. The firm offers a worker a wage equal to the output she produces in excess of the expected output that the next best applicant would have produced. This ensures that the firm earns higher profits when it hires a more productive worker, and so it always hires the most productive applicant for the job.

Section 5 places the firm into an equilibrium environment. I show that there exists a unique equilibrium that satisfies the symmetry restriction on workers' strategies. Moreover, 
the equilibrium is constrained efficient: a social planner who wants to maximize output in the economy but must satisfy the symmetry restriction would choose the same allocation as the decentralized economy. This facilitates my interpretation of some of the results.

Although it is feasible for different types of workers always to apply for different jobs, this does not happen in equilibrium. I prove that if there are at least two types of workers and the distribution of firm characteristics has convex support, there is a positive measure of firms that get applications from at least two types of workers. Firms gather applications from bad workers as insurance against the event that no good workers apply for the job. Thus the model generates equilibrium 'mismatch': there are workers with human capital $h_{1} \neq h_{2}$ and jobs with physical capital $k_{1} \neq k_{2}$, and there is a positive probability that each type of firm hires either type of worker. This makes it possible to ask whether a worker's wage depends only on her human capital, as in the textbook assignment model. On the contrary, I prove that if human and physical capital are complements in production, wages are increasing in physical capital after conditioning on human capital. This is offset by greater competition for jobs with more physical capital, creating more unemployment risk and leaving workers willing to apply for a range of different types of jobs. Similarly, a firm's profit is increasing in the human capital of its employee.

Section 6 analyzes an illustrative special case, the Cobb-Douglas production function, in depth. A worker with human capital $h$ is equally likely to apply for any job with physical capital $k$ above a threshold $K(h)$, increasing in the worker's human capital. This implies that 'mismatch' is widespread, with even the most productive firm hiring an arbitrarily unproductive worker with positive probability. Despite the mismatch, more productive workers on average obtain more productive jobs. Similarly, on average more productive firms hire more productive workers. Thus a weaker notion of assortative matching holds in this environment. With this functional form, I also prove that more productive workers are unemployed less frequently. Although firms hire more productive workers whenever possible, this result is not immediate, since more productive workers also apply for better jobs on average. Finally, I perform two simple comparative statics exercises, showing that an increase in the human capital distribution reduces the employment rate and expected income of a worker conditional on her human capital, while an increase in the physical capital distribution has the opposite effect. The tractability of the Cobb-Douglas case suggests the possibility of a number of extensions to the model, for example to a dynamic framework, to an economy in which workers can apply for multiple jobs within a period, or to an economy with endogenous human and physical capital formation. 
Section 7 considers another special case, an economy with just two types of workers. I prove that if the production function is log supermodular in human and physical capital, a weaker version of positively assortative matching obtains. This generalizes the results from the Cobb-Douglas case, since that production function is weakly log supermodular. Strictly log supermodular production functions have stronger complementarity between human and physical capital. I also prove that with an additively separable production function, which is weakly supermodular but strictly log submodular, matching patterns are described by a weak version of negative sorting. Unlike in a frictionless environment (Becker 1973), supermodularity alone does not imply positively assortative matching.

Section 2 briefly describes the related literature. Section 3 lays out the model, Section 4 describes the solution to a single firm's problem, and Section 5 imbeds the firm's problem in an equilibrium framework and derives a number of general results. Section 6 analyzes the model with a Cobb-Douglas production function in detail, providing closed form solutions for the equilibrium and showing that there is a weak version of positively assortative matching in equilibrium. Section 7 examines assortative matching in an economy with two types of workers. Section 8 concludes.

\section{$2 \quad$ Related Literature}

Montgomery (1991) and Peters (1991) explore the implications of symmetry restrictions in wage or price posting games similar to the one analyzed here. Burdett, Shi, and Wright (2001) refine these analyses, showing that the equilibrium of an economy with a finite number of buyers and sellers converges to the equilibrium of an economy with infinitely many buyers and sellers. They also extend the earlier papers by allowing firms to create more than one vacancy, a possibility that I do not admit.

Three recent papers have extended the wage posting framework to environments with heterogeneous workers and jobs. Coles and Eeckhout (2000) look at an economy with two heterogeneous workers and two heterogeneous jobs, and with complements in production. One of their main results is that the anonymity restriction has no bite in this environment. There is a sense in which this finding is not very surprising, since anonymity only imposes that identical workers must be treated identically, an empty restriction when there are no identical workers. Still, the basic message of Coles and Eeckhout (2000) carries over to my economy: there must be identical workers in order to generate coordination frictions and

mismatch. This raises an important question: do identical workers really exist? Even if 
no two workers are truly identical, it seems reasonable to assume that the millionth most productive worker in the United States economy does not know that she is exactly the millionth most productive worker, and similarly she does not know which is the millionth most productive job. This informational problem will also hinder the coordination of workers' application strategies, raising very similar issues to the ones in this paper.

Shi (2001a) looks at a similar economy to the one in this paper, but implicitly assumes that before search begins, each firm must commit to hire a particular type of worker. Thus firms cannot use applications from bad workers as insurance against not getting an application from a good worker. Although it is still possible that identical firms choose to gather applications from different types of workers, Shi proves that this does not happen in equilibrium. My analysis gives firms the option of committing to hire only one type of worker, for example by offering other types a zero wage, but I prove that in general they choose not to exercise that option. Since in equilibrium firms attract applications from different types of workers, my model generates endogenous mismatch, differential unemployment rates for different workers applying for the same type of job, and a correlation between firm profits and worker productivity after controlling for firm characteristics. None of those results make sense in Shi's equilibrium.

Shi (2001b) does not impose the commitment restriction, making the model fairly similar to the one in this paper. The main technical difference between that paper and this one is that Shi analyzes a model with two types of workers and firms and a Leontief production function, while I consider an arbitrary number of worker types, a continuum of firms, and a much broader class of production functions. Some of Shi's results are similar to those in this paper. For example, under some parameter restrictions, there is mismatch, with less skilled workers applying for both types of jobs with positive probability. In addition, Shi endogenizes firms' entry decisions and considers a number of comparative statics results related to skill-biased technical change that go beyond the scope of this paper. But, Shi does not establish many of the Propositions in Section 5, even within his environment; he does not provide the strong characterization of the equilibrium with a Cobb-Douglas production function in Section 6, since he restricts attention to a Leontief technology; and likewise his characterization of the equilibrium with two types of workers is a special case of my analysis in Section 7.

This paper is also related to random search models with heterogeneous agents (Sattinger 1995, Lu and McAfee 1996, Burdett and Coles 1999, Shimer and Smith 2000). These papers assume workers have no information about jobs and so must randomly look for them. There 
are several advantages to the present model over the random search framework. First, in the random search framework, wage setting is determined outside the model, typically through a Nash bargaining solution. Equilibrium matching patterns depend on the exact specification of the bargaining game, for example the threat points while bargaining. There is no theoretical reason to prefer one specification of the bargaining game over another. Second, the random search framework assumes there is mismatch. With a continuum of job productivity levels, it would take infinitely long for a worker to find a particular type of job, and so necessarily optimizing agents must compromise on their matching pattern. That is not the case in this paper. Indeed, with a Leontief production function, where output is the minimum of the job's physical capital and the worker's human capital, and with identical distributions of workers and jobs in the economy, a worker with human capital $h$ applies only for jobs with physical capital $k=h$, so there is no mismatch. With other production functions, mismatch is a consequence of workers' decision to look for a range of possible jobs, something they could choose not to do.

Third, in the random search model, low productivity workers impose a congestion externality on the search process, making it harder for jobs to meet high productivity workers.

This generates inefficiencies in a decentralized search equilibrium (Shimer and Smith 2001a) and may imply that limit cycles, in which some types of matches are repeatedly created and then destroyed, are more efficient than steady state equilibria (Shimer and Smith 2001b). In the assignment model with coordination frictions, jobs can (and do) choose not to hire bad workers when good ones are available, eliminating the congestion externality. The decentralized equilibrium is unique and efficient, and even in dynamic extensions to the model, there is nothing to be gained by pursuing nonstationary policies. Finally, the random search framework is not very tractable, while this paper demonstrates the possibility of performing some simple cross-sectional comparisons and comparative statics in the assignment model with coordination frictions. At a minimum, the assignment model with coordination frictions provides a useful alternative representation of the job search process.

\section{Model}

\subsection{Participants}

There are two types of risk-neutral agents in the market, workers and firms. There is a measure 1 of workers distinguished by $N$ different human capital levels $0 \leq h_{1}<\cdots<h_{N} \leq$ 
$\bar{h}$. Let $\psi_{n}$ denote the measure of type $h_{n}$ workers in the economy. There is also a measure $\theta$ of firms, each of which is trying to fill a single job. Firms' physical capital $k$ is distributed with a generalized probability distribution $\Phi$ on a subset of $[0, \bar{k}]$. Let $j$, distributed uniformly on $[0, \theta]$, uniquely identify an individual firm and $k_{j}$ denote its physical capital level. Where there is no ambiguity, I sometimes refer to $h$ and $k$ as the worker's and firm's productivity or type.

\subsection{Production}

Workers and firms can match in pairs. Define $f:[0, \bar{h}] \times[0, \bar{k}] \mapsto \mathbb{R}_{+}$, the output that a worker with $h$ units of human capital and a job with $k$ units of physical capital produce as a function of their types, $f(h, k)$. An unmatched agent produces nothing. More generally, one can view $f(h, k)$ as the output produced by a type $h$ worker and type $k$ firm in excess of what they would get while single. For this reason, I assume throughout that $f$ is nonnegative. I also impose that it is increasing in each argument, and hence strictly positive for $k>0$. I sometimes focus on the case where it is strictly supermodular, that is, for all $h<h^{\prime}$ and $k<k^{\prime}, f(h, k)+f\left(h^{\prime}, k^{\prime}\right)>f\left(h, k^{\prime}\right)+f\left(h^{\prime}, k\right)$, or weakly log supermodular, that is, $f(h, k) f\left(h^{\prime}, k^{\prime}\right) \geq f\left(h, k^{\prime}\right) f\left(h^{\prime}, k\right)$. Finally, it will be notationally convenient to introduce a dummy type $h_{0}$ with $f\left(h_{0}, k\right)=0$ for all $k$; this represents what the job produces if it fails to hire any worker.

\subsection{Strategies and Equilibrium Concept}

I represent the assignment problem as a three stage game. In the first stage, each firm $j$ commits to a wage that it will pay a worker if it hires her as a function of her human capital, $w\left(h_{n}, j\right)$. In the second stage, each worker observes all the wage offers and applies for one job, in general using a mixed strategy. In the third stage, firms that receive at least one application hire the most profitable applicant, pay the promised wage, and produce.

In principle, the most productive applicant need not be the most profitable one, the one with the largest difference between output $f\left(h_{n}, k_{j}\right)$ and the promised wage $w\left(h_{n}, j\right)$. I introduce a ranking function $R$ to summarize how firm $j$ chooses between competing applicants, essentially a notion of strict preference. Thus $R\left(h_{n}, h_{m}, j\right)=1$ indicates that firm $j$ always hires a type $h_{n}$ applicant in preference to a type $h_{m}$ applicant. As is standard with strict preferences, I assume $R$ is asymmetric, so $R\left(h_{n}, h_{m}, j\right)=1$ implies $R\left(h_{m}, h_{n}, j\right)=0$. Conversely, I assume that if $m \neq n, R\left(h_{n}, h_{m}, j\right)=0$ implies $R\left(h_{m}, h_{n}, j\right)=1$. I also 
assume that $R$ is transitive, so that if $R\left(h_{n}, h_{m}, j\right)=R\left(h_{m}, h_{l}, j\right)=1, R\left(h_{n}, h_{l}, j\right)=1$ as well. Finally, $R$ encompasses the notion that firms strictly prefer to hire more profitable applicants, so that if $f\left(h_{n}, k_{j}\right)-w\left(h_{n}, j\right)>f\left(h_{m}, k_{j}\right)-w\left(h_{m}, j\right), R\left(h_{n}, h_{m}, j\right)=1$. Note that if $h_{m}$ and $h_{n}$ yield the same profit to firm $j$, I assume $j$ still strictly ranks the applicants, although any ranking is permissible. This affords a significant simplification of the notation at little loss of generality. In particular, it is possible to prove that $j$ would never be able to increase its profits through some randomization strategy.

This game exhibits infinitely many equilibria, including the frictionless assignment. ${ }^{2}$ All jobs offer all workers their wage in the competitive equilibrium, and each worker looks for a different job, with the same assignment as in the decentralized equilibrium. This type of equilibrium is unappealing, since it requires that identical workers know exactly how to sort themselves across jobs. I preclude this possibility by focusing on symmetric subgame perfect equilibria: firms' wage offers and ranking rules depend only on the workers' human capital, and in every subgame, workers with the same level of human capital use the same payoff-maximizing application strategies. Since the frictionless assignment requires that identical workers apply for different jobs, it is ruled out by the symmetry restriction. There is experimental evidence supporting the symmetry assumption in markets with a small finite number of traders (Ochs 1990), and it seems even more plausible in large labor markets.

\subsection{Coordination Friction}

The restriction to symmetric equilibria introduces a coordination friction into the model (Montgomery 1991, Peters 1991, Burdett, Shi, and Wright 2001). Suppose that $x$ workers each apply to a job with independent probability $q / x$. The job expects to get $q$ applications, and the probability it gets exactly $z \in\{0,1,2, \ldots, x\}$ applications is given by a binominal distribution $\frac{x !}{(x-z) ! z !}\left(\frac{q}{x}\right)^{z}\left(1-\frac{q}{x}\right)^{x-z}$. For large $x$, this is well-approximated by a Poisson distribution, i.e. the probability the job gets exactly $z \in\{0,1,2, \ldots\}$ applications is $\frac{q^{z} e^{-q}}{z !}$. Moreover, this result does not depend on the assumption that all the applicants apply for the job with the same probability. This means that there are two ways for a job to be sure to get an applicant: either infinitely many workers must apply for the job with positive probability, so the expected number of applicants is infinite; or some type $h_{n}$ worker must apply for the job with probability 1 . But the symmetry restriction implies that if one type $h_{n}$ worker applies for the job with probability 1 , then so must all the others. Either way, the

\footnotetext{
${ }^{2}$ For details in a related model, see Burdett, Shi, and Wright (2001).
} 
expected number of applicants must be infinite, which is generally not optimal, since only one applicant can get the job.

Let $q\left(h_{n}, j\right)$ denote the expected number of type $h_{n}$ workers applying to job $j$, hereafter referred to as job $j$ 's queue length. This will be a key variable in the analysis of equilibrium. With a finite queue length $q\left(h_{n}, j\right), n=1, \ldots, N$, a job with $k$ units of physical capital is filled by a type $h_{n}$ worker with probability $e^{-\sum_{m=1}^{N} R\left(h_{m}, h_{n}, j\right) q\left(h_{m}, j\right)}\left(1-e^{-q\left(h_{n}, j\right)}\right)$, the product of the probability that the firm does not receive an application from a higher ranked worker and the probability that it receives at least one application from a type $h_{n}$ worker. Conversely, if a type $h_{n}$ worker applies for job $j$, she is hired with probability $e^{-\sum_{m=1}^{N} R\left(h_{m}, h_{n}, j\right) q\left(h_{m}, j\right)} \frac{1-e^{-q\left(h_{n}, j\right)}}{q\left(h_{n}, j\right)}$, the ratio of the probability that the job hires a type $h_{n}$ worker and the expected number of type $h_{n}$ applicants. ${ }^{3}$

\section{A Single Firm's Behavior}

The first and lengthiest step in analyzing the equilibrium of this economy is a partial equilibrium analysis of a single firm's behavior. Firm $j$ sets a wage $w\left(h_{n}, j\right)$ for each type of worker $h_{n}$, taking as given the wages set by the other firms. The promised wages determine the queue of workers $\left\{q\left(h_{n}, j\right)\right\}$ through their application decisions. A firm that offers higher wages will obtain longer queues, since workers will accept lower employment probabilities in return. In what follows, I show that one can think of the firm choosing queues directly, and then back out the implied choice of wages.

\subsection{Profit Function}

Firm $j$ maximizes its expected profit, the product of the probability it hires a type $h_{n}$ worker, $e^{-\sum_{m=1}^{N} R\left(h_{m}, h_{n}, j\right) q\left(h_{m}, j\right)}\left(1-e^{-q\left(h_{n}, j\right)}\right)$, and the resulting revenue in the event it does

\footnotetext{
${ }^{3}$ More formally, the probability that exactly $z$ other type $h_{n}$ workers and no better workers apply for the job is $e^{-\sum_{m=1}^{N} R\left(h_{m}, h_{n}, j\right) q\left(h_{m}, j\right)} \frac{q\left(h_{n}, j\right)^{z} e^{-q\left(h_{n}, j\right)}}{z !}$, in which case the worker is hired with probability $\frac{1}{z+1}$. Summing over $z=0,1, \ldots$ yields a hiring probability of

$$
\begin{aligned}
e^{-\sum_{m=1}^{N} R\left(h_{m}, h_{n}, j\right) q\left(h_{m}, j\right)} \sum_{z=0}^{\infty} \frac{q\left(h_{n}, j\right)^{z} e^{-q\left(h_{n}, j\right)}}{(z+1) !} & =e^{-\sum_{m=1}^{N} R\left(h_{m}, h_{n}, j\right) q\left(h_{m}, j\right)} \frac{\sum_{z=1}^{\infty} \frac{q\left(h_{n}, j\right)^{z} e^{-q\left(h_{n}, j\right)}}{z !}}{q\left(h_{n}, j\right)} \\
& =e^{-\sum_{m=1}^{N} R\left(h_{m}, h_{n}, j\right) q\left(h_{m}, j\right)} \frac{1-e^{-q\left(h_{n}, j\right)}}{q\left(h_{n}, j\right)} .
\end{aligned}
$$
}


so, $f\left(h_{n}, k_{j}\right)-w\left(h_{n}, j\right)$, summed across worker types:

$$
\sum_{n=1}^{N} e^{-\sum_{m=1}^{N} R\left(h_{m}, h_{n}, j\right) q\left(h_{m}, j\right)}\left(1-e^{-q\left(h_{n}, j\right)}\right)\left(f\left(h_{n}, k_{j}\right)-w\left(h_{n}, j\right)\right) .
$$

The firm sets wages recognizing that these will determine the expected queue of workers. To understand the precise relationship between these variables, I turn to workers' payoffs.

\subsection{Utility Function}

The expected utility of a type $h_{n}$ worker, $v\left(h_{n}\right)$, is equal to the highest utility she can get by applying for some job $j$, the product of the promised wage $w\left(h_{n}, j\right)$ and the probability

she is hired conditional on applying for the job $e^{-\sum_{m=1}^{N} R\left(h_{m}, h_{n}, j\right) q\left(h_{m}, j\right)} \frac{1-e^{-q\left(h_{n}, j\right)}}{q\left(h_{n}, j\right)}$. Optimizing behavior by type $h_{n}$ workers implies that they only apply for job $j, q\left(h_{n}, j\right)>0$, if it offers them the highest possible utility,

$$
v\left(h_{n}\right)=e^{-\sum_{m=1}^{N} R\left(h_{m}, h_{n}, j\right) q\left(h_{m}, j\right)} \frac{1-e^{-q\left(h_{n}, j\right)}}{q\left(h_{n}, j\right)} w\left(h_{n}, j\right) .
$$

If the right hand side is smaller than the left hand side, type $h_{n}$ workers would rather apply for a different job, and so $q\left(h_{n}, j\right)=0$. If it is larger, $q\left(h_{n}, j\right)$ will increase until the expected payoff of applying for the job is pushed down to $v\left(h_{n}\right)$. Thus worker optimization implies

$$
q\left(h_{n}, j\right) v\left(h_{n}\right)=e^{-\sum_{m=1}^{N} R\left(h_{m}, h_{n}, j\right) q\left(h_{m}, j\right)}\left(1-e^{-q\left(h_{n}, j\right)}\right) w\left(h_{n}, j\right)
$$

for all $q\left(h_{n}, j\right) \geq 0$. A single firm takes workers' utility $v\left(h_{n}\right)$ as given, so it views equation (2) for each $n=1, \ldots, N$ as summarizing the wage-queue tradeoff.

\subsection{Eliminate Wages}

The firm maximizes profits (1) taking the wage-queue tradeoff (2) as given for each type of worker $h_{n}$. It is easiest to solve this problem by substituting the $N$ constraints into the objective function. The firm simply chooses nonnegative queue lengths $q\left(h_{n}, k\right)$ to maximize

$$
\sum_{n=1}^{N}\left(e^{-\sum_{m=1}^{N} R\left(h_{m}, h_{n}, j\right) q\left(h_{m}, j\right)}\left(1-e^{-q\left(h_{n}, j\right)}\right) f\left(h_{n}, k_{j}\right)-q\left(h_{n}, j\right) v\left(h_{n}\right)\right) .
$$


The first term in the sum is the probability that the firm hires a type $h_{n}$ worker to fill the job times the resulting revenue, while the second term is the expected cost of attracting an applicant queue of $q\left(h_{n}, k\right)$ type $h_{n}$ workers. Viewed this way, the job has a particular production function translating expected applications into expected revenue, and the firm faces a competitive market for applicants with $v\left(h_{n}\right)$ representing the linear cost of type $h_{n}$ applications. This is very nearly a textbook profit maximization problem.

\subsection{Ranking, Part I}

The only odd feature of firm $j$ 's profit function (3) is the ranking function $R$. Although this must be consistent with hiring the most profitable applicant whenever a choice is available, it will simplify the analysis if I temporarily ignore that constraint. Instead, at this point I simply ask what ranking function maximizes profits as written in equation (3). It is easy to confirm algebraically that revenue maximization dictates that firms always hire the most productive applicant. ${ }^{4}$ Intuitively, the ranking function affects the expected revenue generated by queue lengths $\left\{q\left(h_{n}, j\right)\right\}$. Revenue maximization dictates making the most productive use of a given pool of applicants by always hiring the most productive one. However, the ranking function does not affect the expected cost of attaining those queues, $\sum_{n=1}^{N} q\left(h_{n}, j\right) v\left(h_{n}\right)$, since lower ranked workers must be compensated for a low hiring probability with higher wages when they are hired. The expected cost of a type $h_{n}$ applicant is $v\left(h_{n}\right)$, regardless of the hiring probability.

With this motivation, I will temporarily assume that firms hire the most productive applicant, $R\left(h_{m}, h_{n}, j\right)=1$ if and only if $m>n$. I return to this issue in Section 4.9, confirming that optimizing firms set wages consistent with this ranking rule.

\footnotetext{
${ }^{4}$ Suppose there is an $h_{n}>h_{m}$ with $R\left(h_{n}, h_{l}, j\right)=R\left(h_{m}, h_{l}, j\right)$ for all $l \notin\{n, m\}$, and $R\left(h_{n}, h_{m}, j\right)=0$. Switching to $R\left(h_{n}, h_{m}, j\right)=1$ without changing anything else raises profits by

$$
e^{-\sum_{l \notin\{m, n\}} R\left(h_{l}, h_{n}, j\right) q\left(h_{l}, j\right)}\left(1-e^{-q\left(h_{m}, j\right)}\right)\left(1-e^{-q\left(h_{n}, j\right)}\right)\left(f\left(h_{n}, k_{j}\right)-f\left(h_{m}, k_{j}\right)\right),
$$

which is positive since $f\left(h_{n}, k_{j}\right)>f\left(h_{m}, k_{j}\right)$. Thus consecutively ranked types must be ordered according to productivity, and so by extension must everyone else.
} 


\subsection{Existence of a Solution to the Firm's Problem}

With $R\left(h_{m}, h_{n}, j\right)=1$ if and only if $m>n$, the profit function (3) simplifies to

$$
\pi\left(q\left(h_{1}, j\right), \ldots, q\left(h_{N}, j\right), k_{j}\right)=\sum_{n=1}^{N}\left(e^{-Q\left(h_{n}, j\right)}\left(1-e^{-q\left(h_{n}, j\right)}\right) f\left(h_{n}, k_{j}\right)-q\left(h_{n}, j\right) v\left(h_{n}\right)\right)
$$

where $Q\left(h_{n}, j\right) \equiv \sum_{m=n+1}^{N} q\left(h_{m}, j\right)=\sum_{m=1}^{N} R\left(h_{m}, h_{n}, j\right) q\left(h_{m}, j\right)$ is the expected queue of more productive workers applying for the job. Assuming $v\left(h_{n}\right)>0$ for all $n$, Weierstrass's theorem ensures the existence of a solution to the firm's problem. Obviously the firm must choose $q\left(h_{n}, j\right) \geq 0$. If I also introduce an additional constraint $q\left(h_{n}, j\right) \leq \frac{f\left(h_{n}, k_{j}\right)}{v\left(h_{n}\right)}$ for all $n$, then the firm maximizes a continuous function on a compact set, and a solution to the maximization problem exists. But this last artificial constraint is innocuous. The terms $m=n+1, \ldots, N$ in the profit function (4) are unaffected by $q\left(h_{n}, j\right)$, while terms $m=1, \ldots, n-1$ are decreasing in $q\left(h_{n}, j\right)$. Only term $m=n$ is possibly increasing in $q\left(h_{n}, j\right)$. It is equal to zero if $q\left(h_{m}, j\right)=0$, and is negative for all $q\left(h_{n}, j\right) \geq \frac{f\left(h_{n}, k_{j}\right)}{v\left(h_{n}\right)}$. A profit maximizing choice of $q\left(h_{n}, j\right)$ cannot exceed this bound. The artificial constraint is therefore not binding, and the existence result carries over to a firm that is allowed to choose $q\left(h_{n}, j\right)$ larger than $\frac{f\left(h_{n}, k_{j}\right)}{v\left(h_{n}\right)}$. On the other hand, if $v\left(h_{n}\right) \leq 0$, there is no solution to the firm's problem, since it would desire an arbitrarily long queue of these workers. In the remainder of this section, I restrict attention to $v\left(h_{n}\right)>0$, and in Section 5 confirm that any equilibrium has this property.

\subsection{Uniqueness of the Solution to the Firm's Problem}

To prove uniqueness of the solution, I show that the firm's profit function (4) is globally concave in $q$. The first derivative with respect to $q\left(h_{n}, j\right)$ can be expressed as

$$
\frac{\partial \pi\left(q\left(h_{1}, j\right), \ldots, q\left(h_{N}, j\right), k_{j}\right)}{\partial q\left(h_{n}, j\right)}=\sum_{l=1}^{n} e^{-Q\left(h_{l-1}, j\right)}\left(f\left(h_{l}, k_{j}\right)-f\left(h_{l-1}, k_{j}\right)\right)-v\left(h_{n}\right),
$$

and so the second derivative with respect to $q\left(h_{m}, j\right)$ and $q\left(h_{n}, j\right)$ is

$$
\frac{\partial^{2} \pi\left(q\left(h_{1}, j\right), \ldots, q\left(h_{N}, j\right), k_{j}\right)}{\partial q\left(h_{n}, j\right) \partial q\left(h_{m}, j\right)}=-\sum_{l=1}^{\min \langle m, n\rangle} e^{-Q\left(h_{l-1}, j\right)}\left(f\left(h_{l}, k_{j}\right)-f\left(h_{l-1}, k_{j}\right)\right) .
$$


In particular, the Hessian matrix of the profit function can be expressed as the sum of $N$ symmetric $N \times N$ matrices, where matrix $l \in\{1, \ldots, N\}$ has a zero entry in element $\{m, n\}$ if $\min \langle m, n\rangle<l$ and otherwise has an entry of $-e^{-Q\left(h_{l-1}, j\right)}\left(f\left(h_{l}, k_{j}\right)-f\left(h_{l-1}, k_{j}\right)\right)<0$. Pre- and post- multiplying each of these matrices by a non-zero vector $\left(v_{1}, \ldots, v_{N}\right)$ yields a nonpositive number, and a strictly negative number for matrix 1. Summing across these quadratic forms thus gives a negative number,

$$
-\sum_{l=1}^{N}\left(e^{-Q\left(h_{l-1}, j\right)}\left(f\left(h_{l}, k_{j}\right)-f\left(h_{l-1}, k_{j}\right)\right)\left(\sum_{z=l}^{N} v_{z}\right)^{2}\right)
$$

proving the Hessian is negative definite and the profit function is globally concave in $q$.

Uniqueness ensures that any two firms with the same level of physical capital will choose the same queue lengths. With a slight abuse of notation, let $q\left(h_{n}, k\right)$ denote the expected number of type $h_{n}$ applicants for any job with $k$ units of physical capital, and $Q\left(h_{n}, k\right)$ denote the expected queue of more productive applicants.

\subsection{First Order Conditions}

Since the firm's profit maximization problem is globally concave, the standard first order condition is therefore both necessary and sufficient for profit maximization. The condition states that the derivative of the profit function with respect to $q\left(h_{n}, j\right)$, given in expression (5), must equal zero when $q\left(h_{n}, j\right)$ is in the interior of the constraint set, but can be strictly negative at the boundary of the set:

$$
\begin{aligned}
& v\left(h_{n}\right) \geq \sum_{m=1}^{n} e^{-Q\left(h_{m-1}, k\right)}\left(f\left(h_{m}, k\right)-f\left(h_{m-1}, k\right)\right) \\
& \text { and } q\left(h_{n}, k\right) \geq 0 \text { with complementary slackness. }
\end{aligned}
$$

A firm with $k$ units of physical capital attracts applications from type $h_{n}$ workers up to the point where the expected marginal cost of an application $v\left(h_{n}\right)$ is equal to the expected marginal revenue generated by the application, given by the right hand side of the inequality. If $n=1$, condition (6) states that the marginal revenue is equal to the product of the probability that the firm receives no applications, $e^{-Q\left(h_{0}, k\right)}$, and the revenue produced by a type $h_{1}$ worker $f\left(h_{1}, k\right)$ (since $f\left(h_{0}, k\right) \equiv 0$ by construction). More generally, marginal revenue is determined by the increment in production compared to what the firm could have 
produced by hiring a less productive applicant. For example, if $n=2$, marginal revenue is equal to the product of the probability the firm does not get an application from a type $h_{2}$ or better worker, $e^{-Q\left(h_{1}, k\right)}$, times the output produced by a type $h_{2}$ worker in excess of what a type $h_{1}$ worker would produce, $f\left(h_{2}, k\right)-f\left(h_{1}, k\right)$; plus the probability that the firm does not get any applications, $e^{-Q\left(h_{0}, k\right)}$, times the output produced by a type $h_{1}$ worker $f\left(h_{1}, k\right)$. Put differently, expected marginal revenue is equal to the probability the firm hires the worker times the output the worker produces if hired, minus the output that the firm can expect to get from the next best applicant, whose quality and presence is a random variable.

\subsection{Wages}

I now step back and use the first order condition for the choice of queues to back out the firm's wage offers. When $q\left(h_{n}, k\right)>0$, substitute condition (6) into equation (2) to get

$$
w\left(h_{n}, k\right)=\frac{q\left(h_{n}, k\right) e^{-q\left(h_{n}, k\right)}}{1-e^{-q\left(h_{n}, k\right)}} \sum_{m=1}^{n} e^{-\left(Q\left(h_{m-1}, k\right)-Q\left(h_{n-1}, k\right)\right)}\left(f\left(h_{m}, k\right)-f\left(h_{m-1}, k\right)\right)
$$

where with another slight abuse of notation, $w\left(h_{n}, k\right)$ denotes the wage offered to type $h_{n}$ workers by any firm with $k$ units of physical capital. If $q\left(h_{n}, k\right)=0$, a firm with $k$ units of physical capital can offer this wage without attracting applicants from type $h_{n}$ workers, but the model does not pin down the wage uniquely. For example, a zero wage offer would do the same trick.

The first term in the wage offer represents the probability that the job receives exactly one type $h_{n}$ application conditional on receiving at least one such application, the ratio of the probability of receiving exactly one type $h_{n}$ application, $q\left(h_{n}, k\right) e^{-q\left(h_{n}, k\right)}$, to the probability of receiving at least one type $h_{n}$ application, $1-e^{-q\left(h_{n}, k\right)}$. If the job receives an identical application, then the marginal product of the application from the type $h_{n}$ worker is zero. Otherwise, the marginal product is the probability that the next best application is a type $h_{j}<h_{n}$ application, multiplied by the difference in productivity between those workers. This is given by the sum in (7). In words, a worker gets a wage equal to the output she produces in excess of the expected amount that the next best applicant would have produced. This is exactly what the firm would pay to guarantee receiving an application from the worker, reflecting the competitive nature of the decentralized equilibrium. ${ }^{5}$

\footnotetext{
${ }^{5}$ It is also equal to the expected wage that the worker would earn if the firm used a sealed-bid secondprice auction to sell the job to one of the applicants (Julien, Kennes, and King 2000, Shimer 1999). This
} 
The wage does not depend on the expected number of applications from, or the productivity of, workers with more human capital. This is because a type $h_{n}$ worker is only hired, and the wage $w\left(h_{n}, k\right)$ is only paid, when no worker $h_{m}, m>n$, applies for the job. In this event, those issues are immaterial. This highlights an interesting dichotomy in the assignment model with coordination frictions: unemployment is determined by competition from more productive workers, while wages are pinned down by expected competition from less productive workers.

\subsection{Ranking, Part II}

I can now confirm that firms want to hire the most productive job applicant, $f\left(h_{n}, k\right)-$ $w\left(h_{n}, k\right)>f\left(h_{m}, k\right)-w\left(h_{m}, k\right)$ whenever $n>m$. The intuition for this result is quite simple: ex ante, a firm earns higher profits when it hires a more productive worker, and so it would like to rank more productive workers ahead of less productive ones. By doing so, workers anticipate that the firm will hire more productive workers more frequently, and so such workers will still apply for the job at a relatively low wage. Ex post, the low wage reaffirms the firm's preference for hiring more productive workers.

Lemma 1. $f\left(h_{n}, k\right)-w\left(h_{n}, k\right)>f\left(h_{m}, k\right)-w\left(h_{m}, k\right)$ whenever $n>m$ and $q\left(h_{n}, k\right)$ and $q\left(h_{m}, k\right)$ are positive, so firms always hire the most productive job applicant.

Proof. Take any $h_{m}>h_{b}$ with $q\left(h_{n}, k\right)>0, q\left(h_{m}, k\right)>0$ and $q\left(h_{z}, k\right)=0$ for all $h_{n}<$ $h_{z}<h_{m} \cdot \frac{q\left(h_{n}, k\right)}{1-e^{-q\left(h_{n}, k\right)}}>1$, since this is the inverse of the probability that a type $h_{n}$ worker is hired when she applies for a job with no more productive job applicants. Thus equation (7) implies

$$
\begin{aligned}
w\left(h_{n}, k\right) & >e^{-q\left(h_{n}, k\right)} \sum_{l=1}^{n} e^{-\left(Q\left(h_{l-1}, k\right)-Q\left(h_{n-1}, k\right)\right)}\left(f\left(h_{l}, k\right)-f\left(h_{l-1}, k\right)\right) \\
& =\sum_{l=1}^{n} e^{-\left(Q\left(h_{l-1}, k\right)-Q\left(h_{n}, k\right)\right)}\left(f\left(h_{l}, k\right)-f\left(h_{l-1}, k\right)\right)
\end{aligned}
$$

Similarly, $q\left(h_{m}, k\right)>0$ implies $\frac{q\left(h_{m}, k\right) e^{-q\left(h_{m}, k\right)}}{1-e^{-q\left(h_{m}, k\right)}}<1$, since this is the probability that the job receives no identical applications conditional on hiring a type $h_{m}$ worker. Thus equation (7)

suggests that existing results on the equivalence between auctions and ex ante wage commitments (e.g. Kultti 1999, Julien, Kennes, and King 2001) should extend to environments with heterogeneous workers and firms. 
implies

$$
w\left(h_{m}, k\right)<\sum_{l=1}^{m} e^{-\left(Q\left(h_{l-1}, k\right)-Q\left(h_{m-1}, k\right)\right)}\left(f\left(h_{l}, k\right)-f\left(h_{l-1}, k\right)\right)
$$

Subtracting the first inequality from the second gives

$$
\begin{aligned}
w\left(h_{m}, k\right)-w\left(h_{n}, k\right)<\sum_{l=n+1}^{m} e^{-\left(Q\left(h_{l-1}, k\right)-Q\left(h_{m-1}, k\right)\right)}\left(f\left(h_{l}, k\right)-f\left(h_{l-1}, k\right)\right) \\
\quad+\left(e^{Q\left(h_{m-1}, k\right)}-e^{Q\left(h_{n}, k\right)}\right) \sum_{l=1}^{n} e^{-Q\left(h_{l-1}, k\right)}\left(f\left(h_{l}, k\right)-f\left(h_{l-1}, k\right)\right)
\end{aligned}
$$

Further simplify this using the assumption that $q\left(h_{z}, k\right)=0$ for all $h_{n}<h_{z}<h_{m}$, or equivalently $Q\left(h_{z}, k\right)=Q\left(h_{n}, k\right)$ for all $h_{n} \leq h_{z}<h_{m}$. All the exponents in the first sum are zero, while the second line is zero since $Q\left(h_{n}, k\right)=Q\left(h_{m-1}, k\right)$ :

$$
w\left(h_{m}, k\right)-w\left(h_{n}, k\right)<\sum_{l=n+1}^{m}\left(f\left(h_{l}, k\right)-f\left(h_{l-1}, k\right)\right)=f\left(h_{m}, k\right)-f\left(h_{n}, k\right),
$$

as desired. Extends this using transitivity to arbitrary positive $q\left(h_{m}, k\right)$ and $q\left(h_{n}, k\right)$.

\subsection{Summary of a Single Firm's Behavior}

The following proposition summarizes these results:

Proposition 1. A firm with $k$ units of physical capital takes the vector of worker's utility $\left\{v\left(h_{n}\right)\right\}$ as given and chooses the vector of queue lengths $\left\{q\left(h_{n}, k\right)\right\} \geq 0$ to maximize profits (4). Queue lengths satisfy the complementary slackness condition (6) and are uniquely defined if $\left\{v\left(h_{n}\right)\right\}$ is strictly positive. The firm obtains this queue by offering a wage schedule (7). The firm always hires the most productive applicant for the job.

\section{Equilibrium}

Section 4 looked at a single firm's profit maximization problem, taking the vector of worker's utility $\left\{v\left(h_{n}\right)\right\}$ as given. When the economy is in equilibrium, however, $\left\{v\left(h_{n}\right)\right\}$ is determined endogenously. The notion of labor market equilibrium is standard. For any 'prices' $\left\{v\left(h_{n}\right)\right\}$, calculate the demand for each type of labor by each type of firm, $\left\{q\left(h_{n}, k\right)\right\}$, uniquely defined by the complementary slackness condition (6). Sum across firms to get the total demand for 
type $h_{n}$ labor, $\theta \int_{0}^{\bar{k}} q\left(h_{n}, k\right) d \Phi(k)$. The labor market is in equilibrium if the demand for each type of labor is equal to the inelastic supply of that type of labor $\psi_{n}$ :

$$
\psi_{n}=\theta \int_{0}^{\bar{k}} q\left(h_{n}, k\right) d \Phi(k)
$$

where $q\left(h_{n}, k\right)$ is consistent with the first order condition (6).

\subsection{Existence}

The first step in establishing the existence of an equilibrium is proving that $v\left(h_{i}\right)$ is bounded above zero. Fix any capital stock $\underline{k}>0$ with $\Phi(\underline{k})<1$. Then sum the resource constraint $(8)$ across the $N$ types of workers to get

$$
1 \geq \theta \int_{\underline{k}}^{\bar{k}} Q\left(h_{0}, k\right) d \Phi(k),
$$

and so in particular there must be some $k \in[\underline{k}, \bar{k}]$ with $Q\left(h_{0}, k\right) \leq \frac{1}{\theta(1-\Phi(\underline{k}))}$. Also, condition (6) implies that for all $h_{n}$,

$$
v\left(h_{n}\right) \geq e^{-Q\left(h_{0}, k\right)} f\left(h_{n}, k\right) \geq e^{-1 / \theta(1-\Phi(\underline{k}))} f\left(h_{n}, \underline{k}\right) \equiv \underline{v}\left(h_{n}\right),
$$

where the second inequality uses $Q\left(h_{0}, k\right) \leq \frac{1}{\theta(1-\Phi(\underline{k}))}$ and $f\left(h_{n}, k\right) \geq f\left(h_{n}, \underline{k}\right)$. This provides a strictly positive lower bound on the equilibrium value $v\left(h_{n}\right)$. It is also possible to find an upper bound on the equilibrium value of $v\left(h_{n}\right)$. If $v\left(h_{n}\right) \geq f\left(h_{n}, \bar{k}\right)$, condition (6) implies $q\left(h_{n}, k\right)=0$ for all $k \in[0, \bar{k}]$, inconsistent with equilibrium.

Next, for any positive value of the vector $\left\{v\left(h_{n}\right)\right\}$, let $\left\{q\left(h_{n}, k\right)\right\}$ denote the profit maximizing queue lengths of each firm $k$, uniquely defined by Proposition 1 . Using these, define the excess demand for type $h_{n}$ workers by $X_{n} \equiv \theta \int_{0}^{\bar{k}} q\left(h_{n}, k\right) d \Phi(k)-\psi_{n}$. Now consider the operator $T_{n}$ that updates $v\left(h_{n}\right)$ to $v\left(h_{n}\right)+X_{n}$, truncated at $\left[\underline{v}\left(h_{n}\right), f\left(h_{n}, \bar{k}\right)\right]$. That is, if $v\left(h_{n}\right)+X_{n}>f\left(h_{n}, \bar{k}\right)$, the new value of $v\left(h_{n}\right)$ is $f\left(h_{n}, \bar{k}\right)$. If $v\left(h_{n}\right)+X_{n}<\underline{v}\left(h_{n}\right)$, the new value of $v\left(h_{n}\right)$ is $\underline{v}\left(h_{n}\right)$. Otherwise the new value is $v\left(h_{n}\right)+X_{n}$. Let $T \equiv$ $T_{1} \times \cdots \times T_{N}$ denote the associated composite mapping. $T$ is continuous since $\left\{q\left(h_{n}, k\right)\right\}$ is continuous in $\left\{v\left(h_{n}\right)\right\}$ by Berge's (1963) Theorem of the Maximum. Moreover, T maps $\left[\underline{v}\left(h_{1}\right), f\left(h_{1}, \bar{k}\right)\right] \times\left[\underline{v}\left(h_{N}\right), f\left(h_{N}, \bar{k}\right)\right]$ into itself by construction. Brouwer's theorem therefore ensures that the mapping has a fixed point. 
All that remains is to prove that a fixed point is an equilibrium price vector. First suppose there is a fixed point with $v\left(h_{n}\right)=f\left(h_{n}, \bar{k}\right)$ for some $h_{n}$. This implies $q\left(h_{n}, k\right)=0$ for all $k$, so $X_{n}=-\psi_{n}$. The updating rule then yields a new value of $v\left(h_{n}\right)<f\left(h_{n}, \bar{k}\right)$, contradicting the assumption that this is a fixed point. Alternatively, suppose there is a fixed point with $v\left(h_{n}\right)=\underline{v}\left(h_{n}\right)$ for some $h_{n}$. By construction, at this low value of $v\left(h_{n}\right)$, there must be excess demand for some type of worker, say $h_{m} \geq h_{n}$ with $X_{m}>0$. The only way that the updating rule would not increase $v\left(h_{m}\right)$ is if it is already equal to $f\left(h_{m}, \bar{k}\right)$, a possibility already ruled out. This means that at any fixed point, $v\left(h_{n}\right) \in\left(\underline{v}\left(h_{n}\right), f\left(h_{n}, \bar{k}\right)\right)$ for all $h_{n}$. Such interior values are fixed points only if there is no excess demand, $X_{n}=0$, completing the proof.

\subsection{Uniqueness and Efficiency}

Rather than prove uniqueness of the decentralized equilibrium directly, it is easier to analyze a related centralized problem. Consider a hypothetical social planner who selects $q\left(h_{n}, k\right) \geq 0$ for all firms $k$ given the resource constraint (8). Assume the social planner is constrained by the same symmetry restriction as the decentralized economy, and so cannot direct identical workers towards different firms. This policy then yields output

$$
\int_{0}^{\bar{k}} \sum_{n=1}^{N}\left(e^{-Q\left(h_{n}, k\right)}\left(1-e^{-q\left(h_{n}, k\right)}\right) f\left(h_{n}, k\right)\right) d \Phi(k) .
$$

Express the planner's output maximization problem as a Lagrangian with multiplier $\frac{v\left(h_{n}\right)}{\theta}$ on the resource constraint (8):

$$
\int_{0}^{\bar{k}} \sum_{n=1}^{N}\left(e^{-Q\left(h_{n}, k\right)}\left(1-e^{-q\left(h_{n}, k\right)}\right) f\left(h_{n}, k\right)+\left(\frac{\psi_{n}}{\theta}-q\left(h_{n}, k\right)\right) v\left(h_{n}\right)\right) d \Phi(k) .
$$

Although here $v\left(h_{n}\right)$ represents a shadow wage, a comparison with (4) establishes that the social planner effectively maximizes the sum of firms' profits with a given shadow wage $v\left(h_{n}\right)$. The Kuhn-Tucker theorem then ensures that any decentralized equilibrium solves the planner's problem, maximizing output. Finally, the proof that the firm's profit function is concave in $q$ carries over to the centralized problem as well. There is at most one solution to the planner's problem, ${ }^{6}$ hence a unique decentralized equilibrium. In summary:

\footnotetext{
${ }^{6}$ A technical caveat is in order here. The social planner can behave suboptimally on a set of measure zero $k$ without lowering output, yielding a trivial multiplicity of solutions to the planner's problem. Nevertheless, $v\left(h_{n}\right)$ is pinned down uniquely by the social planner's problem.
} 
Proposition 2. There exists a unique decentralized equilibrium in this economy. The equilibrium maximizes the value of output subject to the coordination friction.

This result contrasts sharply with results in random search models with heterogeneous agents. Sattinger (1995) and Burdett and Coles (1997) establish the existence of multiple equilibria. Shimer and Smith (2001a) show that none of the equilibria decentralize the social optimum, with some agents too willing to accept matches and others too reluctant. Acemoglu (1996) and Davis (2001) focus on another inefficiency: workers and firms generally underinvest in human and physical capital in random search environments.

\subsection{Mismatch}

Workers can segregate themselves, for example with more productive workers always applying for more productive jobs, but in equilibrium they choose not to do so. As long as there are at least two types of workers, it is possible to find an interval of physical capital levels that receive applications from both types of workers. If the physical capital distribution has convex support, this interval will include a positive measure of firms. And within that group of firms, in any realization of the mixed strategies, it is possible to find both a more productive firm that hires a less productive worker and a more productive firm that hires a more productive worker, relative to the two less productive firms. I refer to this phenomenon as mismatch, since any physical capital to human capital matching pattern is possible.

Proposition 3. Assume $N \geq 2$ and the support of the physical capital distribution is convex. A positive measure of jobs receive applications from at least two types of workers, generating mismatch.

Proof. First, suppose a type $k$ job optimally receives no applications, $q(h, k)=0$ for all $h$. Condition (6) simplifies to $v\left(h_{n}\right) \geq f\left(h_{n}, k\right)$, so the cost of an application from a type $h_{n}$ worker is higher than the amount she produces, even if she is hired with probability one whenever she applies for the job. Monotonicity of $f$ ensures that this must also be true for all less productive jobs $k^{\prime}<k$. In other words, there is a threshold $\underline{k}<\bar{k}$ such that workers only apply for jobs above the threshold, and all jobs above the threshold receive some applications.

Next, if all jobs only received applications from one type of worker, it is possible to partition the jobs $k \geq \underline{k}$ into those jobs that receive applications from type $h_{n}$ workers, $n=1, \ldots, N$. By definition, the partition consists of nonintersecting sets, each with positive 
measure and with union $[\underline{k}, \bar{k}]$. Not all of these sets can be closed, so there must be points $k \in(\underline{k}, \bar{k})$ such that $k$ is in one element of the partitions, say the set of jobs that receive applications from type $h$ workers, but is a limit point of another set. In other words, it is possible to find a sequence $\left\{k^{z}\right\}$ converging to $k$, with $q\left(h, k^{z}\right)=0$, but $q(h, k)>0$, so $q(h, \cdot)$ is discountinuous at $k$. However, Berge's (1963) Theorem of the Maximum implies $q(h, \cdot)$ is continuous in $k$, since the profit maximization problem is continuous in $k$ and has exactly one solution. This is a contradiction, which implies that there are some jobs that receive applications from two types of workers, $q\left(h_{m}, k\right)>0$ and $q\left(h_{n}, k\right)>0$ for $m \neq n$. Continuity of $q$ ensures these inequalities hold for nearby $k$. If the support of the physical capital distribution is convex, this region must include a positive measure of jobs $k$.

This Proposition depends on the assumption that the production function is strictly increasing. ${ }^{7}$ Consider the Leontief production function $f(h, k)=\min \langle h, k\rangle$. Assume that the human capital and physical capital distributions are identical, although the firm-worker ratio $\theta$ need not be equal to one. I claim that in equilibrium, queue lengths satisfy $q\left(h_{n}, h_{n}\right)=\theta^{-1}$ and $q\left(h_{n}, k\right)=0$ otherwise, while $v\left(h_{n}\right)=e^{-1 / \theta} h_{n}$. It is easy to verify that this satisfies the resource constraint (8). Also, since $Q\left(h_{n-1}, k\right)=\theta^{-1}$ if $k \geq h_{n}$ and zero otherwise, condition (6) reduces to $e^{-1 / \theta} h_{n} \geq e^{-1 / \theta} \min \left\langle h_{n}, k\right\rangle$ for $k=h_{1}, \ldots h_{N}$. This is always satisfied, and it holds as an equality for $k \geq h_{n}$, and in particular whenever $q\left(h_{n}, k\right)>0$. Now consider the limit as the number of human capital levels goes to infinity, and the human and physical capital distributions converge to any atomless limit $\Phi$. The basic characterization of equilibrium holds in this limiting economy as well, and in particular, no firm receives applications from more than one type of worker.

\subsection{Empirical Predictions}

According to the textbook assignment model (Sattinger 1993), a worker's wage should be determined by her characteristics, not by her job. However, econometricians usually find that in a regression of wages on a worker's characteristics, much of the residual can be explained through the characteristics of her job (Krueger and Summers 1988, Groshen 1991, Gibbons and Katz 1992, Abowd, Kramarz, and Margolis 1999). One possible explanation is unobserved worker heterogeneity (Murphy and Topel 1987). Since more productive workers

\footnotetext{
${ }^{7}$ If output were not strictly increasing, aggregate output would not be a strictly concave function of the queues, and so the social optimum need not be uniquely defined. It follows that multiple equilibria can exist. The Theorem of the Maximum still applies, but it only tells us that the set of profit maximizing queues is upper hemicontinuous in $k$. This eliminates a crucial piece used in the proof of Proposition 3.
} 
get better jobs, the job reveals something about the worker's productivity that is observable to firms but unobservable to the econometrician. But that does not seem to be the whole story. For example, Krueger and Summers (1988) and Gibbons and Katz (1992) find that workers who move from a high to a low wage firm lose approximately the wage differential between the two firms. Another explanation is that workers in some industries receive a compensating differential. Again, this explanation appears to be incomplete, since Krueger and Summers (1988) find that industry fixed effects have little explanatory power. Most wage dispersion appears to be at the level of individual firms.

This paper provides a concise explanation that is consistent with this evidence. A single type of worker typically opts to search over a range of different types of jobs. A worker who earns a high wage relative to her characteristics opted to seek a high wage, high productivity job, and was lucky enough to find one. The presence of firm effects in a wage regression is thus a classic sample selection problem: the econometrician does not observe the workers who seek but fail to find high wage jobs.

The key to this explanation is that more productive jobs pay higher wages. This is true if the production function is supermodular: for all $h_{2}>h_{1}$ and $k_{2}>k_{1}, f\left(h_{2}, k_{2}\right)+f\left(h_{1}, k_{1}\right)>$ $f\left(h_{2}, k_{1}\right)+f\left(h_{1}, k_{2}\right)$. Of course, supermodularity is also implicitly assumed in the unobserved heterogeneity explanation, since this restriction ensures that more productive workers are assigned to better jobs in a frictionless environment.

Proposition 4. Assume $f$ is strictly supermodular. Then $Q(h, k)$ is strictly increasing in $k$ whenever it is positive and $w(h, k)$ is increasing in $k$ whenever $q(h, k)$ is positive. Thus there is a positive correlation between a worker's wage $w(h, k)$ and the quality of her job $k$ after conditioning on worker characteristics $h$.

Proof. The bulk of the proof consists of showing that $Q$ is increasing in $k$. Recall that $Q\left(h_{N}, k\right)=0$ by construction. Now, to find a contradiction, suppose there exists an $n<N$ and a $k<k^{\prime}$ with $Q\left(h_{n}, k\right)>0$ and $Q\left(h_{n}, k\right) \geq Q\left(h_{n}, k^{\prime}\right)$. Since $Q\left(h_{n}, k\right)>0$, it is possible to find an $n^{\prime} \geq n+1$ with $Q\left(h_{n}, k\right)=Q\left(h_{n^{\prime}-1}, k\right)>Q\left(h_{n^{\prime}}, k\right)$, i.e. the least productive worker who is more productive than $h_{n}$ and whom $k$ attracts with positive probability. Since $Q$ is nonincreasing in $h, Q\left(h_{n}, k^{\prime}\right) \geq Q\left(h_{n^{\prime}-1}, k^{\prime}\right)$, and so by transitivity, $Q\left(h_{n^{\prime}-1}, k\right) \geq Q\left(h_{n^{\prime}-1}, k^{\prime}\right)$ as well.

Since $k$ attracts $h_{n^{\prime}}$ but $k^{\prime}$ does not necessarily do so, (6) binds in the first case but not 
necessarily in the second:

$$
\sum_{m=1}^{n^{\prime}} e^{-Q\left(h_{m-1}, k\right)}\left(f\left(h_{m}, k\right)-f\left(h_{m-1}, k\right)\right) \geq \sum_{m=1}^{n^{\prime}} e^{-Q\left(h_{m-1}, k^{\prime}\right)}\left(f\left(h_{m}, k^{\prime}\right)-f\left(h_{m-1}, k^{\prime}\right)\right)
$$

Strict supermodularity implies $f\left(h_{m}, k\right)-f\left(h_{m-1}, k\right)<f\left(h_{m}, k^{\prime}\right)-f\left(h_{m-1}, k^{\prime}\right)$ for all $m$ since $k<k^{\prime}$, and so (10) implies $\sum_{m=1}^{n^{\prime}} e^{-Q\left(h_{m-1}, k\right)}>\sum_{m=1}^{n^{\prime}} e^{-Q\left(h_{m-1}, k^{\prime}\right)}$. This precludes the possibility of $Q\left(h_{m-1}, k\right) \geq Q\left(h_{m-1}, k^{\prime}\right)$ for all $m=1, \cdots, n^{\prime}$. Pick the largest $n^{\prime \prime} \in\left\{1, \ldots, n^{\prime}\right\}$ with $Q\left(h_{n^{\prime \prime}-1}, k\right)<Q\left(h_{n^{\prime \prime}-1}, k^{\prime}\right)$. Since by construction $Q\left(h_{n^{\prime}-1}, k\right) \geq Q\left(h_{n^{\prime}-1}, k^{\prime}\right)$, in fact $n^{\prime \prime} \in\left\{1, \ldots, n^{\prime}-1\right\}$. Note that if $n^{\prime}=1$, there is no such $n^{\prime \prime}$, finishing the proof.

Once again, monotonicity of $Q$ ensures that $Q\left(h_{n^{\prime \prime}}, k\right) \leq Q\left(h_{n^{\prime \prime}-1}, k\right)$, and since by construction $Q\left(h_{n^{\prime \prime}}, k^{\prime}\right) \leq Q\left(h_{n^{\prime \prime}}, k\right)$, transitivity implies $Q\left(h_{n^{\prime \prime}}, k^{\prime}\right)<Q\left(h_{n^{\prime \prime}-1}, k^{\prime}\right) \equiv Q\left(h_{n^{\prime \prime}}, k^{\prime}\right)+$ $q\left(h_{n^{\prime \prime}}, k^{\prime}\right)$, i.e. $q\left(h_{n^{\prime \prime}}, k^{\prime}\right)>0$, so $k^{\prime}$ attracts applications from type $h_{n^{\prime \prime}}$ workers. Again appeal to (6), now binding for $k^{\prime}$ but not necessarily for $k$ :

$$
\sum_{m=1}^{n^{\prime \prime}} e^{-Q\left(h_{m-1}, k\right)}\left(f\left(h_{m}, k\right)-f\left(h_{m-1}, k\right)\right) \leq \sum_{m=1}^{n^{\prime \prime}} e^{-Q\left(h_{m-1}, k^{\prime}\right)}\left(f\left(h_{m}, k^{\prime}\right)-f\left(h_{m-1}, k^{\prime}\right)\right)
$$

Now subtract this from $(10)$, noting that $n^{\prime \prime}<n^{\prime}$ to get

$$
\sum_{m=n^{\prime \prime}+1}^{n^{\prime}} e^{-Q\left(h_{m-1}, k\right)}\left(f\left(h_{m}, k\right)-f\left(h_{m-1}, k\right)\right) \geq \sum_{m=n^{\prime \prime}+1}^{n^{\prime}} e^{-Q\left(h_{m-1}, k^{\prime}\right)}\left(f\left(h_{m}, k^{\prime}\right)-f\left(h_{m-1}, k^{\prime}\right)\right)
$$

However, by construction $Q\left(h_{m-1}, k\right) \geq Q\left(h_{m-1}, k^{\prime}\right)$ and so $e^{-Q\left(h_{m-1}, k\right)} \leq e^{-Q\left(h_{m-1}, k^{\prime}\right)}$ for $m \in$ $\left\{n^{\prime \prime}+1, \ldots n^{\prime}\right\}$, while supermodularity implies $f\left(h_{m}, k\right)-f\left(h_{m-1}, k\right)<f\left(h_{m}, k^{\prime}\right)-f\left(h_{m-1}, k^{\prime}\right)$ for these $m$ as well. This clearly contradicts the final inequality, proving that $Q\left(h_{n}, k\right)$ is increasing in $k$ when it is positive.

To prove $w\left(h_{n}, k\right)$ is also increasing in $k$, recall that the probability $h_{n}$ is hired by $k$ when she applies for the job is

$$
e^{-Q\left(h_{n}, k\right)} \frac{1-e^{-q\left(h_{n}, k\right)}}{q\left(h_{n}, k\right)}=\frac{e^{-Q\left(h_{n}, k\right)}-e^{-Q\left(h_{n-1}, k\right)}}{Q\left(h_{n-1}, k\right)-Q\left(h_{n}, k\right)},
$$

where the second expression uses $q\left(h_{n}, k\right)=Q\left(h_{n-1}, k\right)-Q\left(h_{n}, k\right)$ to obtain a more convenient expression. Simple differentiation shows that the hiring probability is decreasing both in $Q\left(h_{n}, k\right)$ and in $Q\left(h_{n-1}, k\right)$, and thus decreasing in $k$. Since $h_{n}$ is less likely to get hired 
in jobs with higher $k$, equation (2) implies that she must be compensated with a higher wage.

An additional implication of Proposition 4 is that more productive firms attract more applicants, $Q\left(h_{0}, k\right)$ is increasing in $k$. This is consistent with the observation by Holzer, Katz, and Krueger (1991) that high wage firms attract significantly more applicants.

It is not necessarily true that more productive workers get higher wages at a given job, $w(h, k)$ need not be increasing in $h$. A slightly less productive worker may be much less likely to be hired, in which case firms may compensate her with a much higher wage. In Section $6, \mathrm{I}$ construct an example in which wages depend on physical capital $k$ but not on human capital $h$. By perturbing the example, one can therefore get either correlation between wages and human capital after conditioning on physical capital.

A related implication of the model is that after conditioning on firm characteristics, establishments that hire workers with better observable characteristics should earn higher profits. This follows trivially from Lemma 1, and requires only monotonicity of the production function. I restate the result for expositional purposes:

Proposition 5. $f(h, k)-w(h, k)$ is increasing in $h$ whenever $q(h, k)$ is positive. Thus there is a positive correlation between a firm's profit $f(h, k)-w(h, k)$ and the quality of its employee $h$ after conditioning on firm characteristics $k$.

The correlation between a firm's profit $f(h, k)-w(h, k)$ and the quality of its worker $h$ after conditioning on firm's characteristic $k$ reflects that some firms potentially get applications from multiple types of workers, and that some of these firms are luckier than others, hiring workers with more human capital and earning higher profits. There is less evidence in support of this Proposition, since an empirical investigation must utilize a matched worker-firm data set to measure both firm profits and worker characteristics. To my knowledge, the only direct test of this hypothesis is contained in recent work by Abowd, Kramarz, and Margolis (1999) using French data. Table X on page 298 shows that a firm's profits, measured as the ratio of operating income divided by capital stock, is increasing in its workers' observable characteristics ('Average Predicted Effect of $x$ Variables $(x \beta)^{\prime}$ ). Moreover, Abowd, Kramarz, and Margolis follow workers over time, and so include individual fixed effects in their regression to control for unobserved heterogeneity. They find that workers' unobserved characteristics have a small and statistically insignificant effect on firm profits. An important caveats in interpreting these results is that my model does not capture the institutional 
structure of the French labor market, e.g. high minimum wage levels and centralized bargaining. Nonetheless, existing empirical evidence on the correlation between firm profits and worker characteristics is consistent with the model.

A random search model with heterogeneous agents also delivers within group wage and profit inequality, since some agents are luckier than others. However, neither Proposition 4 nor Proposition 5 holds in such a model, at least if wages are determined by Nash bargaining. Shimer and Smith (2000) show that with a Constant Elasticity of Substitution production function with elasticity of substitution less than or equal to 1, the surplus that a worker gets is a continuous single-peaked function of the characteristics of the job, increasing in $k$ at low values but typically obtaining an interior maximum and then decreasing for higher values of $k$. Thus there is no reason to expect any particular correlation between wages and physical capital after conditioning on human capital. The same is true for firms: profits are decreasing in the worker's human capital for high values of $h$ because the negotiated wage is very high, and so there is no obvious correlation between profits and human capital after conditioning on physical capital. Any empirical evidence in support of these Propositions favors the assignment model with search frictions in preference to the random search model.

\section{Cobb-Douglas Production Function}

In this section, I analyze a special case in considerable detail, providing closed-form solutions that help to make the analysis more concrete. I assume that the production function is CobbDouglas, $f(h, k)=A h^{\alpha} k^{\beta}$, with positive parameters $A, \alpha$, and $\beta$, and that the distribution of physical capital is $\Phi(k)=k^{\gamma}$ on $[0,1]$ for some $\gamma>0$. Imposing restrictions on $\alpha+\beta$, e.g. constant returns to scale, is unnecessary.

\subsection{Equilibrium}

Begin by defining $K(h)$ as the solution to

$$
K(h)^{\gamma}-\log K(h)^{\gamma} \equiv 1+\frac{\gamma}{\beta \theta}(1-\Psi(h))
$$

$0<K(h)<1$, where $\Psi\left(h_{n}\right) \equiv \sum_{m=1}^{n-1} \psi_{m}$ denotes the fraction of the labor force with lower productivity than $h_{n}$, a cumulative distribution function. $K(h)$ is increasing in $\Psi(h)$, and so this forms an increasing sequence of numbers, $0<K\left(h_{1}\right)<\cdots K\left(h_{N}\right)<1$. Then I claim 
that in equilibrium, type $h_{n}$ workers have value $v\left(h_{n}\right)=A \sum_{m=1}^{n}\left(h_{m}^{\alpha}-h_{m-1}^{\alpha}\right) K\left(h_{m}\right)^{\beta}$, and queue lengths are given by

$$
q\left(h_{n}, k\right)= \begin{cases}0 & k \in\left[0, K\left(h_{n}\right)\right] \\ \beta \log \frac{k}{K\left(h_{n}\right)} & \text { if } \quad k \in\left(K\left(h_{n}\right), K\left(h_{n+1}\right)\right] \\ \beta \log \frac{K\left(h_{n+1}\right)}{K\left(h_{n}\right)} & k \in\left(K\left(h_{n+1}\right), 1\right]\end{cases}
$$

so $Q\left(h_{n-1}, k\right)=\beta \log \frac{k}{K\left(h_{n}\right)}$ for $k \in\left[K\left(h_{n}\right), 1\right]$ and zero otherwise. In other words, type $h_{n}$ workers apply for all jobs above the threshold $K\left(h_{n}\right)$. They are equally likely to apply for all jobs above the next threshold $K\left(h_{n+1}\right)$, and somewhat less likely to apply for jobs between $K\left(h_{n}\right)$ and $K\left(h_{n+1}\right)$.

It is easy to verify that the resource constraint (8) is satisfied with these queue lengths by substitution:

$$
\begin{aligned}
\psi_{n} & =\beta \theta\left(\int_{K\left(h_{n}\right)}^{K\left(h_{n+1}\right)} \log \left(\frac{k}{K\left(h_{n}\right)}\right) \gamma k^{\gamma-1} d k+\left(1-K\left(h_{n+1}\right)^{\gamma}\right) \log \frac{K\left(h_{n+1}\right)}{K\left(h_{n}\right)}\right) \\
& =\frac{\beta \theta}{\gamma}\left(K\left(h_{n}\right)^{\gamma}-\log K\left(h_{n}\right)^{\gamma}-K\left(h_{n+1}\right)^{\gamma}+\log K\left(h_{n+1}\right)^{\gamma}\right)=\Psi\left(h_{n+1}\right)-\Psi\left(h_{n}\right)
\end{aligned}
$$

where the third expression is derived from the second by integration and the fourth from the third by substituting for $K\left(h_{n}\right)^{\gamma}-\log K\left(h_{n}\right)^{\gamma}$ and $K\left(h_{n+1}\right)^{\gamma}-\log K\left(h_{n+1}\right)^{\gamma}$ using the definition (11). Condition (6) can also be verified by substitution:

$$
A \sum_{m=1}^{n}\left(h_{m}^{\alpha}-h_{m-1}^{\alpha}\right) K\left(h_{m}\right)^{\beta} \geq A \sum_{m=1}^{n}\left(h_{m}^{\alpha}-h_{m-1}^{\alpha}\right) \min \left\langle K\left(h_{m}\right), k\right\rangle^{\beta}
$$

which holds as an equality if and only if $k \geq K\left(h_{n}\right)$. This confirms that the prescribed queue and worker's value form an equilibrium, and Proposition 2 ensures uniqueness.

Curiously, workers' application decisions depend only on their percentile in the human capital distribution, not on the level of their human capital. It makes sense that doubling each worker's human capital should not affect application decisions, since that simply raises output by a factor of $2^{\alpha}$, but it is more surprising that nonlinear convolutions of the human capital distribution also do not affect applications.

No worker applies for a job below the least productive worker $h_{1}$ 's threshold $K\left(h_{1}\right)>0$, the solution to $K\left(h_{1}\right)^{\gamma}-\log K\left(h_{1}\right)^{\gamma} \equiv 1+\frac{\gamma}{\beta \theta}$. This means that for any distribution of human capital, a positive measure of jobs with physical capital $0<k<K\left(h_{1}\right)$ never get 
any applications. These jobs do not congest the labor market, and the equilibrium would be unchanged if they did not exist. Nonetheless, their presence is interesting. The jobs remain vacant with probability one, yet they coexist with unemployment. Any worker could guarantee herself a job by applying to one of them, but in equilibrium this is not worthwhile. The worker would rather risk unemployment to get a higher wage at a higher productivity job. The existence of this fringe of available vacancies suggests a formal definition of voluntary unemployment as workers who can get jobs with probability one but choose to enter lengthy job queues instead. Of course, voluntary unemployment, like all unemployment in this model, is efficient in the sense that it maximizes aggregate output.

\subsection{Continuous-Type Limit}

It is easier to characterize the equilibrium if there is a large number of worker types, approximated through a continuous density. Let $\Psi(h)$ denote an atomless cumulative distribution function, and define $K(h)$ as in (11). Take an arbitrary sequence of models with a discrete worker distribution converging to the atomless distribution $\Psi(h)$. Then it is readily verified that in the continuous-type limit, the density of type $h$ applications to type $k$ firms, $\tilde{q}(h, k) \equiv-\frac{\partial Q(h, k)}{\partial h}$, satisfies

$$
\tilde{q}(h, k)=\left\{\begin{array}{lll}
0 & & k \in[0, K(h)) \\
\beta \frac{K^{\prime}(h)}{K(h)} & \text { if } & k \in[K(h), 1]
\end{array} .\right.
$$

Also, $Q(h, k)=\beta \log \frac{k}{K(h)}$ if $k>K(h)$ and $Q(h, k)=0$ otherwise. Thus type $h$ workers are equally likely to apply for any job above their threshold $K(h)$, using a uniform distribution in deciding where to apply.

In the limiting economy, the expected income of a type $h$ worker converges to

$$
v(h)=A \alpha \int_{\underline{h}}^{h} i^{\alpha-1} K(i)^{\beta} d i+A \underline{h}^{\alpha-1} K(\underline{h})^{\beta}
$$

where $\underline{h}$ is the lower bound on the human capital distribution. In particular, $v^{\prime}(h)=$ $A \alpha h^{\alpha-1} K(h)^{\beta}$, a standard pricing equation in frictionless assignment models (Sattinger 1993), setting the marginal cost of a type $h$ worker equal to the marginal product of the worker in a job with physical capital $K(h)$. In a standard frictionless assignment model, $K(h)$ would be the one type of job that $h$ is assigned to in equilibrium. With coordination frictions, it is the worst type of job that $h$ applies for, or equivalently the job that she is sure 
to get.

The wage equation (7) also simplifies in the limiting economy, since there is no chance that a firm receives multiple applications from the same type of worker. Any firm with $k \geq K(h)$ units of physical capital offers worker $h$ a wage

$$
w(h, k)=A\left(\frac{k}{K(h)}\right)^{\beta}\left(\alpha \int_{\underline{h}}^{h} i^{\alpha-1} K(i)^{\beta} d i+\underline{h}^{\alpha} K(\underline{h})^{\beta}\right) .
$$

Because the characterization of the limiting economy is somewhat simpler than the characterization of the economy with a discrete number of worker types, in what follows I focus on the limiting economy. All the results also carry over to the discrete-type economy.

\subsection{Wages and Human Capital}

Proposition 4 proves that a worker's wage is increasing in the physical capital of her job as long as the production function is supermodular. It need not be the case, however, that a firm's wage offer is increasing in the human capital of its worker, as the following example illustrates: $f(h, k)=A h k ; \phi(k)=1$ on $[0,1]($ so $\alpha=\beta=\gamma=1) ; \Psi(h)=1+e(h-1)-e^{h-1}$

on $[1,2]$; and $\theta=e$. Then (11) implies $K(h)=e^{h-2} \in\left[e^{-1}, 1\right]$, while substituting into equation (12) implies $\tilde{q}(h, k)=1$ if $k>K(h)$ and is zero otherwise. Substituting these results into equation (13) yields a simple formula for firms' wage offers, $w(h, k)=A k$, independent of the worker's human capital. By perturbing the example, it is easy to construct examples in which the wage is either increasing or decreasing in $h$.

This example provides one possible explanation for why many firms' wage offers are not very sensitive to the human capital of their employees. High productivity applicants are compensated primarily through an increased hiring probability rather than through the wage. Of course, the example is not generic, and so one would be very surprised if the optimal wage offer were completely independent of human capital. But the example illustrates that even in generic environments, firms may not lose much by offering a single wage. It is easy to imagine the lost profits being made up by not having to verify the worker's human capital.

\subsection{Employment Rates}

More productive workers are employed more often. The finding might not seem surprising, since they are at the front of job queues, but there is an effect working in the opposite direction. Less productive workers apply for some jobs that more productive ones pass over. 
To prove this result, I calculate the employment rate directly. A type $h$ worker is equally likely to apply for any job above her threshold $k>K(h)$, facing an employment rate of $e^{-Q(h, k)}=(K(h) / k)^{\beta}$ in such a job. This implies that on average she is employed with probability $\operatorname{emp}(h)$, given by

$$
\operatorname{emp}(h)=\frac{\int_{K(h)}^{1}(K(h) / k)^{\beta} \gamma k^{\gamma-1} d k}{1-K(h)^{\gamma}}=\frac{\gamma\left(K(h)^{\beta}-K(h)^{\gamma}\right)}{(\gamma-\beta)\left(1-K(h)^{\gamma}\right)}
$$

or $\frac{-K(h)^{\beta} \log K(h)^{\beta}}{1-K(h)}$ if $\gamma=\beta$. This is increasing in $K(h)$, hence increasing in $h$. For the highest type, $K(h)=\operatorname{emp}(h)=1$, so she is always employed. Such a worker never finds herself behind another on a job queue. On the other hand, the unemployment rate of the least productive worker may be very high. In the example from the previous section with $\alpha=\beta=\gamma=1, \Psi(h)=1+e(h-1)-e^{h-1}$ on $[1,2]$, and $\theta=e, \operatorname{emp}(h)=\frac{2-h}{e^{2-h}-1}$, so $\operatorname{emp}(0) \approx 0.58$. That is, the least productive worker is unemployed approximately $42 \%$ of the time. ${ }^{8}$ By applying for a job at or below her threshold $K(0)=e^{-1}$, she would be guaranteed employment, and would be able to produce a positive amount of output.

\subsection{Weak Assortative Matching}

Consider an econometrician who has access to a data set containing a matched sample of workers and jobs. An observation consists of the human capital of an employed worker $h$, drawn randomly from the employed population, and the physical capital of her job $k$. According to the frictionless assignment model, if the production function is supermodular, the $n^{\text {th }}$ most productive worker in the data set should be employed in the $n^{\text {th }}$ most productive job. In other words, the rank correlation coefficient should be equal to one. This result does not generalize to the assignment model with coordination frictions since there is mismatch. Nevertheless, I show in this section that with a Cobb-Douglas matching function, more productive workers generally obtain more productive jobs and more productive firms generally hire more productive workers. In particular, the rank correlation coefficient is positive, a notion that I call 'weak assortative matching'.

A type $h$ worker is equally likely to apply for any job above her threshold $K(h)$, but, conditional on applying for it, she obtains a type $k \geq K(h)$ job with probability $e^{-Q(h, k)}=$ $(K(h) / k)^{\beta}$, decreasing in $k$. This means that the physical capital of worker $h$ 's employer

\footnotetext{
${ }^{8}$ Since this is a one-shot game, unemployment rates are very high. With additional employment opportunities in future periods, the rates would naturally come down.
} 
is a random variable with cumulative distribution $\frac{k^{\gamma-\beta}-K(h)^{\gamma-\beta}}{1-K(h)^{\gamma-\beta}}$ for $k>K(h)$, and limit $1-\frac{\log k}{\log K(h)}$ when $\gamma=\beta$. The distribution of jobs for more productive workers first order stochastically dominates the distribution for less productive workers.

A similar argument establishes that the distribution of worker characteristics at a firm with $k$ units of physical capital and an employee is a random variable with distribution $\frac{K(h)^{\beta}-K(0)^{\beta}}{k^{\beta}-K(0)^{\beta}}$. This is decreasing in $k$, so more productive firms hire more productive workers in the sense of first order stochastic dominance.

In principle, it is possible to test for first order stochastic dominance using nonparameteric techniques in a sufficiently large data set. In practice, however, the data demands may be unrealistic. Thus it is useful to understand some weaker and more easily testable implications of the assignment model with coordination frictions. First order stochastic dominance implies that the observed mean level of physical capital conditional on a worker's human capital, $E(k \mid h)$, should be increasing in the worker's human capital. Likewise, the expected rank order of the job's physical capital within the data set of filled jobs, $\tilde{\Phi}(k)$, should be increasing in the rank order of the worker's human capital, $\tilde{\Psi}(h)$. Conversely, $E(h \mid k)$ and $E(\tilde{\Psi}(h) \mid \tilde{\Phi}(k))$ should be increasing in $k$ and $\tilde{\Phi}(k)$, respectively.

A much weaker prediction is that the correlation and the rank correlation between matched human and physical capital should be positive. To see this, consider the following string of equalities:

$$
\begin{aligned}
\operatorname{cov}(h, k)=E((h-E(h))(k-E(k))) & =E((h-E(h))(E(k \mid h)-E(k))) \\
& =E\left(\left(h-h_{0}\right)(E(k \mid h)-E(k))\right)>0
\end{aligned}
$$

where $h_{0}$ is defined by $E\left(k \mid h_{0}\right) \equiv E(k)$. The first equality uses the definition of covariance, the second uses the law of iterated expectations, $E(h E(k \mid h))=E(h k)$, and the third uses the fact that both $E(h)$ and $h_{0}$ are numbers, and so the product of either constant with $E(E(k \mid h)-E(k))$ is zero. The inequality then follows immediately from the definition of $h_{0}$ and the assumed monotonicity of $E(k \mid h)$. For $h>h_{0}, E(k \mid h)>E(k)$, and so the product inside the inequality is positive. It is also positive for $h<h_{0}$, since then $E(k \mid h)<E(k)$. Finally, correlation and covariance always share the same sign, since their ratio is the product of the standard deviations of $h$ and $k$. A similar proof works for rank correlations.

Finally, but more hypothetically, suppose an econometrician had access to a data set consisting of an unemployed worker's human capital and the physical capital of a job that she applies for. The model also yields first order stochastic dominance relationships for this 
type of data. More productive workers apply for more productive jobs, and more productive firms get applications from more productive workers. Hence weak assortative matching carries over to such a data set.

\subsection{Comparative Statics}

The model is sufficiently tractable so as to be amenable to comparative statics. Consider an increase in workers' human capital, represented by an decrease in $\Psi(h)$ for all $h$. This reduces the threshold $K(h)$ for all $h$, so a worker whose human capital is unchanged applies for less productive jobs on average, is unemployed more frequently, and earns a lower expected income $v(h)$.

Of course, the increase in skills is likely to induce a shift in firm's physical capital in the long run, and so it is natural to also consider the effect of an increase in $\gamma \cdot{ }^{9}$ This raises $K(h)$ for all $h$, so workers seek jobs with more physical capital, as one might expect. Since the expected income of a type $h$ worker is $K(h)$, it follows that expected income rises as well. Finally, $K(h)^{\gamma}$, the percentile of a type $h$ worker's minimally acceptable job, falls. This means there is less competition for the top jobs, reducing the unemployment rate. In other words, the endogenous response of the physical capital distribution to an increase in workers' human capital is likely to offset much of the effects discussed in the previous paragraph

\section{Two Types of Workers}

This section focuses on generalizing the assortative matching results to other production functions. Unfortunately, I am unable to provide a useful characterization of matching patterns with arbitrary production functions and an arbitrary number of worker types. I instead assume that there are only two types of workers, $N=2$. I show that whether matching is assortative depends on whether the production function $f(h, k)$ is log supermodular. ${ }^{10}$

\footnotetext{
${ }^{9}$ Studying the equilibrium response of firms' investment to shifts in the human capital distribution goes beyond the scope of this model. See Shi (2001b) for a related model with endogenous physical capital choice.

${ }^{10}$ Together with the standard assumptions that $f$ is nonnegative and increasing, log supermodularity implies supermodularity. For example, within the class of Constant Elasticity of Substitution production functions, log supermodularity imposes that the elasticity of substitution between human and physical capital is less than unity, its value in the Cobb-Douglas case.
} 


\subsection{Log-Supermodular Production Function}

Assume that the production function is log supermodular. Rather than providing a closed form solution, I focus on how equilibrium queue lengths depend on the endogenous price of applications $v\left(h_{1}\right)$ and $v\left(h_{2}\right)$. My analysis imposes only a very weak equilibrium condition on the model, that some type of firm $k$ must be willing to hire type $h_{1}$ workers. Define three physical capital levels $k^{a}$ by $v\left(h_{1}\right) \equiv f\left(h_{1}, k^{a}\right) ; k^{b}$ by $v\left(h_{2}\right)-v\left(h_{1}\right) \equiv f\left(h_{2}, k^{b}\right)-f\left(h_{1}, k^{b}\right)$; and $k^{c}$ by $\frac{v\left(h_{2}\right)}{v\left(h_{1}\right)} \equiv \frac{f\left(h_{2}, k^{c}\right)}{f\left(h_{1}, k^{c}\right)}$. Note that the right hand side of each definition is increasing in $k$ since $f$ is monotonic, supermodular, and log supermodular. Thus there is at most one solution to each equation. For now assume that a solution exists to each equation. Then I claim that in equilibrium $k^{a}<k^{b}<k^{c}$, and queue lengths are given by

$$
q\left(h_{1}, k\right)=\left\{\begin{array}{lr}
0 & k \leq k^{a} \\
\log f\left(h_{1}, k\right)-\log v\left(h_{1}\right) & \text { if } \begin{array}{l}
k \in\left(k^{a}, k^{b}\right] \\
\log \frac{f\left(h_{1}, k\right)}{f\left(h_{2}, k\right)-f\left(h_{1}, k\right)}-\log \frac{v\left(h_{1}\right)}{v\left(h_{2}\right)-v\left(h_{1}\right)}
\end{array} \\
0 & k \in\left(k^{b}, k^{c}\right) \\
0 & k \geq k^{c}
\end{array}\right.
$$

and

$$
q\left(h_{2}, k\right)= \begin{cases}0 & k \leq k^{b} \\ \log \left(f\left(h_{2}, k\right)-f\left(h_{1}, k\right)\right)-\log \left(v\left(h_{2}\right)-v\left(h_{1}\right)\right) & \text { if } \quad k \in\left(k^{b}, k^{c}\right] \\ \log f\left(h_{2}, k\right)-\log v\left(h_{2}\right) & k>k^{c}\end{cases}
$$

I prove this result in steps. First, observe that $k^{a} \gtreqless k^{b} \Longleftrightarrow k^{b} \gtreqless k^{c}: k^{a}>k^{b}$ implies $v\left(h_{1}\right)>f\left(h_{1}, k^{b}\right)$ since $f$ is increasing. Divide $v\left(h_{2}\right)-v\left(h_{1}\right)=f\left(h_{2}, k^{b}\right)-f\left(h_{1}, k^{b}\right)$ by this inequality to get $\frac{v\left(h_{2}\right)}{v\left(h_{1}\right)}<\frac{f\left(h_{2}, k^{b}\right)}{f\left(h_{1}, k^{b}\right)}$. Log supermodularity of $f$ implies $\frac{f\left(h_{2}, k\right)}{f\left(h_{1}, k\right)}$ is increasing in $k$, and hence that $k^{b}>k^{c}$. The proofs with $k^{a}=k^{b}$ and $k^{a}<k^{b}$ are identical.

I next prove that $k^{a}<k^{b}<k^{c}$ in any equilibrium. There must be some $k$ with $q\left(h_{1}, k\right)>$ 0. If also $q\left(h_{2}, k\right)>0$, (6) implies

$$
v\left(h_{1}\right)=e^{-\left(q\left(h_{1}, k\right)+q\left(h_{2}, k\right)\right)} f\left(h_{1}, k\right) \text { and } v\left(h_{2}\right)=e^{-q\left(h_{2}, k\right)}\left(f\left(h_{2}, k\right)-f\left(h_{1}, k\right)\right)+v\left(h_{1}\right) .
$$

Since $e^{-q\left(h_{1}, k\right)}<1$, the first equality implies $v\left(h_{1}\right)<e^{-q\left(h_{2}, k\right)} f\left(h_{1}, k\right)$. Use the second equality to reduce this to $\frac{v\left(h_{2}\right)}{v\left(h_{1}\right)}>\frac{f\left(h_{2}, k\right)}{f\left(h_{1}, k\right)}$ or $k<k^{c}$. Also, since $e^{-q\left(h_{2}, k\right)}<1$, the second equality implies $v\left(h_{2}\right)-v\left(h_{1}\right)<f\left(h_{2}, k\right)-f\left(h_{1}, k\right)$ or $k>k^{b}$. That is, if $q\left(h_{1}, k\right)>0$ and 
$q\left(h_{2}, k\right)>0, k^{a}<k^{b}<k<k^{c}$. Alternatively, if $q\left(h_{2}, k\right)=0,(6)$ implies

$$
v\left(h_{1}\right)=e^{-q\left(h_{1}, k\right)} f\left(h_{1}, k\right) \text { and } v\left(h_{2}\right) \geq f\left(h_{2}, k\right)-f\left(h_{1}, k\right)+v\left(h_{1}\right) .
$$

Since $e^{-q\left(h_{1}, k\right)}<1$, the equality implies $v\left(h_{1}\right)<f\left(h_{1}, k\right)$ or $k>k^{a}$. The inequality directly implies $k \leq k^{b}$. That is, if $q\left(h_{1}, k\right)>0$ and $q\left(h_{2}, k\right)=0, k^{a}<k \leq k^{b}<k^{c}$. Either way, $k^{a}<k^{b}<k^{c}$.

Next consider what happens if $q\left(h_{1}, k\right)=0$. If $q\left(h_{2}, k\right)>0,(6)$ implies

$$
v\left(h_{1}\right) \geq e^{-q\left(h_{2}, k\right)} f\left(h_{1}, k\right) \text { and } v\left(h_{2}\right)=e^{-q\left(h_{2}, k\right)} f\left(h_{2}, k\right) .
$$

Substituting the equality into the inequality yields $\frac{v\left(h_{2}\right)}{v\left(h_{1}\right)} \leq \frac{f\left(h_{2}, k\right)}{f\left(h_{1}, k\right)}$, so $k \geq k^{c}$ in this case. On the other hand, if $q\left(h_{2}, k\right)=0$, (6) implies

$$
v\left(h_{1}\right) \geq f\left(h_{1}, k\right) \text { and } v\left(h_{2}\right) \geq f\left(h_{2}, k\right)
$$

The first inequality implies $k \leq k^{a}$.

Finally, I can use these same results to solve explicitly for $q\left(h_{1}, k\right)$ and $q\left(h_{2}, k\right)$. For example, suppose $q\left(h_{1}, k\right)>0$ and $q\left(h_{2}, k\right)=0$ so $k^{a}<k \leq k^{b}$. Then solve $v\left(h_{1}\right)=$ $e^{-q\left(h_{1}, k\right)} f\left(h_{1}, k\right)$ for $q\left(h_{1}, k\right)$ to get the expression in the statement of the proof. The other cases are identical.

If one or more of the points $k^{a}, k^{b}$, or $k^{c}$ is not defined, the appropriate region of the parameter space disappears. Consider the Constant Elasticity of Substitution production function $f(h, k)=\left(\alpha h^{\rho}+(1-\alpha) k^{\rho}\right)^{1 / \rho}$ with elasticity of substitution $\frac{1}{1-\rho}$ less than one, or equivalently $\rho<0$. For all $k \geq 0$ and $h_{1}<h_{2}$, it is easy to show that $\frac{f\left(h_{2}, k\right)}{f\left(h_{1}, k\right)}<\frac{h_{2}}{h_{1}}$. This means that if $\frac{v\left(h_{2}\right)}{v\left(h_{1}\right)}>\frac{h_{2}}{h_{1}}$, there is no value of $k$ such that $q\left(h_{2}, k\right)>0$ and $q\left(h_{1}, k\right)=0$. Effectively, $k^{c}=\infty$, so $q\left(h_{1}, k\right)>0$ for all $k>k^{a}$. The same result carries over to the Cobb-Douglas case, and so in fact the analysis in this section requires only weak log supermodularity of the production function. ${ }^{11}$

Using the expressions for $q\left(h_{1}, k\right)$ and $q\left(h_{2}, k\right)$ in equations (14) and (15), it is easy to prove that assortative matching carries over to this environment, with more productive

\footnotetext{
${ }^{11}$ There are also values of $v\left(h_{i}\right)$ such that $v\left(h_{2}\right)-v\left(h_{1}\right)>f\left(h_{2}, k\right)-f\left(h_{1}, k\right)$ for all $k$, since the latter is bound above by $\alpha^{1 / \rho}\left(h_{2}-h_{1}\right)$. This would appear to imply $k^{b}=\infty$ as well, but that is not quite correct. For a type $k$ firm to hire a type $h_{2}$ worker, it must be the case that $v\left(h_{2}\right)-v\left(h_{1}\right)<f\left(h_{2}, k\right)-f\left(h_{1}, k\right)$, and so a global failure of this inequality is inconsistent with any firm hiring a type $h_{2}$ worker, hence inconsistent with equilibrium.
} 
workers generally obtaining more productive jobs. The distributions of a type $h_{1}$ and a type $h_{2}$ worker's job is

$$
\frac{\int_{0}^{k} e^{-q\left(h_{2}, l\right)}\left(1-e^{-q\left(h_{1}, l\right)}\right) d \Phi(l)}{\int_{0}^{\bar{k}} e^{-q\left(h_{2}, l\right)}\left(1-e^{-q\left(h_{1}, l\right)}\right) d \Phi(l)} \geq \frac{\int_{0}^{k}\left(1-e^{-q\left(h_{2}, l\right)}\right) d \Phi(l)}{\int_{0}^{\bar{k}}\left(1-e^{-q\left(h_{2}, l\right)}\right) d \Phi(l)}
$$

respectively. The numerator on the left hand side integrates the probability that a type $l$ firm hires a type $h_{1}$ worker, $e^{-q\left(h_{2}, l\right)}\left(1-e^{-q\left(h_{1}, l\right)}\right)$, multiplied by the density of type $l$ firms, over all firm types below $k$. This is converted to a distribution by an appropriate denominator. The right hand side performs a similar calculation for the type $h_{2}$ firms. To see why the inequality holds, observe that the integrand in the numerator of the left hand side is increasing for $l \in\left(k^{a}, k^{b}\right)$, since $q\left(h_{1}, l\right)$ is increasing and $q\left(h_{2}, l\right)=0$; it is decreasing for $l \in\left(k^{b}, k^{c}\right)$, since $q\left(h_{1}, l\right)$ is decreasing and $q\left(h_{2}, l\right)$ is increasing; and otherwise it is equal to zero. The integrand in the numerator of the right hand side is increasing for $l>k^{b}$ and is otherwise equal to zero. This yields a single crossing property of the densities, which in turn ensures first order stochastic dominance of the distributions. Similarly, more productive firms are relatively more likely to hire a type $h_{2}$ worker than a type $h_{1}$ worker.

\subsection{Additively Separable Production Function}

The assumption that the production function is log supermodular is crucial to this assortative matching result. Suppose $f(h, k)=\alpha h+\beta k$, the limit of Constant Elasticity of Substitution production functions as the elasticity of substitution goes to infinity, and a log submodular production function. The characterization of equilibrium qualitatively changes. Define physical capital levels $k^{a}$ by $v\left(h_{2}\right) \equiv \alpha h_{2}+\beta k^{a}$ and $k^{b}$ by $\frac{v\left(h_{2}\right)}{v\left(h_{1}\right)} \equiv \frac{\alpha h_{2}+\beta k^{b}}{\alpha h_{1}+\beta k^{b}}$. Then in equilibrium,

$$
q\left(h_{1}, k\right)= \begin{cases}0 & \text { if } \begin{array}{l}
k \leq k^{b} \\
\log \frac{\alpha h_{1}+\beta k}{\alpha\left(h_{2}-h_{1}\right)}-\log \frac{v\left(h_{1}\right)}{v\left(h_{2}\right)-v\left(h_{1}\right)} \quad
\end{array} \quad k>k^{b}\end{cases}
$$

and

$$
q\left(h_{2}, k\right)= \begin{cases}0 & k \leq k^{a} \\ \log \left(\alpha h_{2}+\beta k\right)-\log v\left(h_{2}\right) & \text { if } \quad k \in\left(k^{a}, k^{b}\right] \\ \log \left(\alpha\left(h_{2}-h_{1}\right)\right)-\log \left(v\left(h_{2}\right)-v\left(h_{1}\right)\right) & k>k^{b}\end{cases}
$$


Curiously, there is no region of the parameter space with $q\left(h_{1}, k\right)>0$ and $q\left(h_{2}, k\right)=0$. To see why, note first that Proposition 3 ensures that there must be mismatch, some $k$ with both $q\left(h_{1}, k\right)>0$ and $q\left(h_{2}, k\right)>0$. For such a $k$, condition $(6)$ implies $v\left(h_{2}\right)-v\left(h_{1}\right)=$ $e^{-q\left(h_{2}, k\right)} \alpha\left(h_{2}-h_{1}\right)$. This provides a restriction

$$
v\left(h_{2}\right)-v\left(h_{1}\right)<\alpha\left(h_{2}-h_{1}\right)
$$

that is independent of $k$, and so must be satisfied in any equilibrium. But now note that if ever $q\left(h_{1}, k\right)>0$ and $q\left(h_{2}, k\right)=0$, (6) implies $v\left(h_{2}\right)-v\left(h_{1}\right) \geq \alpha\left(h_{2}-h_{1}\right)$, which is impossible.

The restriction (16) also implies that $k^{b}>k^{a}$. Otherwise, if $k^{b} \leq k^{a}, \frac{v\left(h_{2}\right)}{v\left(h_{1}\right)} \geq \frac{\alpha h_{2}+\beta k^{a}}{\alpha h_{1}+\beta k^{a}}$, since the right hand side is decreasing in $k$. Combining this with $v\left(h_{2}\right) \equiv \alpha h_{2}+\beta k^{a}$ yields $v\left(h_{2}\right)-v\left(h_{1}\right) \geq \alpha\left(h_{2}-h_{1}\right)$, a contradiction. The remainder of the proof follows the structure of the argument for the log supermodular case, and so is omitted.

Low productivity workers only apply to high productivity firms, $k>\bar{k}$, and with queue lengths increasing in the firms' productivity. High productivity workers also apply for lower productivity firms, with an increasing queue length for $k \in(\underline{k}, \bar{k})$, and thereafter a constant queue length. This reverses the structure of applications in the log supermodular case. On average, more productive firms hire less productive workers, negatively assortative matching.

The intuition for this result follows from thinking about the output-maximizing assignment of workers to jobs, which is the same as the equilibrium assignment (Proposition 2). High productivity workers should be spread across as many jobs as possible, so as to ensure that they are employed. However, there is no sense in sending a low productivity worker to a low productivity job, since little output is gained. Rather, low productivity workers should queue at high productivity jobs, making sure that these firms hire someone. This carries over to nearby supermodular but log submodular production functions, e.g. Constant Elasticity of Substitution functions with a high elasticity of substitution between human and physical capital.

\section{Conclusion}

The assignment model with coordination frictions explains a rich set of interactions between heterogeneous workers and firms. It is also tractable, particularly in some special cases, such as the Cobb-Douglas. It should therefore lend itself to a number of extensions. In concluding, I will mention only three. 
First, as noted in the comparative statics exercises with the Cobb-Douglas production function, there are some questions that are most naturally asked in a model with endogenous physical capital investments. The close link between the equilibrium of this model and the competitive equilibrium of the market for job applicants, as well as earlier work by Acemoglu and Shimer (1999) and Shi (2001a), suggest that some of the results, for example efficiency of the decentralized equilibrium, are robust to this extension.

Second, I have assumed that workers can only apply for one job. There are conceptual difficulties in allowing workers to apply for multiple jobs simultaneously: can firms make 'second-round' offers in the event their first offer is turned down? Albrecht, Gautier, and Vroman (2001) analyze a version of this model with homogeneous workers and firms, showing that the basic properties of the model carry over to an environment with second round offers.

Third, the model should be extended to a dynamic framework if it is to be taken quantitatively seriously. The extension should also have some qualitative effects on the results. For example, I showed that with a Cobb-Douglas production function, the most productive firms attract applications from all workers. In a dynamic model, these firms would refuse to hire very unproductive workers, and so low productivity workers would not apply for the job. This would likely strengthen the assortative matching results discussed in Sections 6 and 7 .

\section{References}

Abowd, John, Francis Kramarz, and David Margolis (1999): "High Wage Workers and High Wage Firms," Econometrica, 67(2), 251-333.

Acemoglu, Daron (1996): "A Microfoundation for Social Increasing Returns in Human Capital Accumulation," Quarterly Journal of Economics, 111(3), 779-804.

Acemoglu, Daron, and Robert Shimer (1999): "Holdups and Efficiency with Search Frictions," International Economic Review, 40(4), 827-851.

Albrecht, James, Pieter Gautier, and Susan Vroman (2001): "Matching with Multiple Applications," Georgetown Mimeo.

Becker, Gary (1973): "A Theory of Marriage: Part I," Journal of Political Economy, $81(4), 813-846$.

Berge, Claude (1963): Topological Spaces. Macmillan, New York. 
Burdett, Kenneth, and Melvyn Coles (1997): "Marriage and Class," Quarterly Journal of Economics, 112(1), 141-68.

(1999): "Long-Term Partnership Formation: Marriage and Employment," Economic Journal, 109(456), F307-F334.

Burdett, Kenneth, Shouyong Shi, and Randall Wright (2001): "Pricing and Matching with Frictions," Journal of Political Economy, Forthcoming.

Coles, Melvyn, and Jan Eeckhout (2000): "Efficient Job Allocation,” Mimeo.

Davis, Steven (2001): "The Quality Distribution of Jobs and the Structure of Wages in Search Equilibrium," NBER Working Paper 8434.

Gibbons, Robert, and Lawrence Katz (1992): "Does Unmeasured Ability Explain Inter-Industry Wage Differentials," Review of Economic Studies, 59(3), 515-535.

Groshen, Erica (1991): "Sources of Intra-Industry Wage Dispersion: How Much Do Employers Matter?," Quarterly Journal of Economics, 106(3), 869-884.

Holzer, Harry, Lawrence Katz, and Alan Krueger (1991): "Job Queues and Wages," Quarterly Journal of Economics, 106(3), 739-768.

Julien, Benoit, John Kennes, and Ian P. King (2000): "Bidding for Labor," Review of Economic Dynamics, 3(4), 619-649.

- (2001): "Auctions and Posted Prices in Directed Search Equilibrium," Topics in Macroeconomics (BE Journals in Macroeconomics), 1(1), Article 1.

Koopmans, TJalling, and Martin Beckmann (1957): "Assignment Problems and the Location of Economic Activities," Econometrica, 25(1), 53-76.

Krueger, Alan, and Lawrence Summers (1988): "Efficiency Wages and the InterIndustry Wage Structure," Econometrica, 56(2), 259-293.

Kultti, Klaus (1999): "Equivalence of Auctions and Posted Prices," Games and Economic Behavior, 27(1), 106-113.

Lu, Xiaohua, and R. Preston McAfee (1996): "Matching and Expectations in a Market with Heterogeneous Agents," in Advances in Applied Microeconomics, ed. by Michael Baye, vol. 6, pp. 121-156. JAI Press, Greenwich, CT.

Montgomery, James (1991): "Equilibrium Wage Dispersion and Interindustry Wage Differentials," Quarterly Journal of Economics, 106(1), 163-179. 
Murphy, Kevin, And Robert Topel (1987): "Unemployment, Risk and Earnings: Testing for Equalizing Wage Differences in the Labor Market," in Unemployment and the Structure of Labor Markets, ed. by Kevin Lang, and Jonathan Leonard. Basil Blackwell, Oxford.

OCHS, JACK (1990): "The Coordination Problem in Decentralized Markets: An Experiment," Quarterly Journal of Economics, 105(2), 545-559.

Peters, Michael (1991): "Ex Ante Price Offers in Matching Games: Non-Steady States," Econometrica, 59(5), 1425-1454.

Roth, Alvin, And Marilda Sotomayor (1990): Two-Sided Matching: A Study in Game-Theoretic Modeling and Analysis. Cambridge University Press, Cambridge.

Sattinger, Michael (1993): "Assignment Models of the Distribution of Earnings," Journal of Economic Literature, 31(2), 831-880.

- (1995): "Search and the Efficient Assignment of Workers to Jobs," International Economic Review, 36(2), 283-302.

Shapley, Lloyd, And Martin Shubik (1972): "The Assignment Game I: the Core," International Journal of Game Theory, 1(2), 111-130.

Shi, Shouyong (2001a): "Frictional Assignment, Part I: Efficiency," Journal of Economic Theory, 98(2), 232-260.

(2001b): "A Wage-Posting Model of Inequality and Heterogeneous Skills and SkillBiased Technology," Indiana University Mimeo.

Shimer, Robert (1999): "Job Auctions," Princeton Mimeo.

Shimer, Robert, And Lones Smith (2000): "Assortative Matching and Search," Econometrica, 68(2), 343-370.

(2001a): "Matching, Search, and Heterogeneity," Advances in Macroeconomics (BE Journals in Macroeconomics), 1(1), Article 5.

— (2001b): "Nonstationary Search," Mimeo. 